\title{
Global mapping and characterization of Titan's dune fields with Cassini: Correlation between RADAR and VIMS observations
}

\author{
S. Rodriguez ${ }^{\text {a,* }}$, A. Garcia ${ }^{\mathrm{a}}$, A. Lucas ${ }^{\mathrm{a}}$, T. Appéré ${ }^{\mathrm{a}}$, A. Le Gall ${ }^{\mathrm{b}}$, E. Reffet $^{\mathrm{a}}$, L. Le Corre ${ }^{\mathrm{c}}$, S. Le Mouélic $^{\mathrm{d}}$, \\ T. Cornet ${ }^{\mathrm{d}}$, S. Courrech du Pont ${ }^{\mathrm{e}}$, C. Narteau ${ }^{\mathrm{f}}$, O. Bourgeois ${ }^{\mathrm{d}}$, J. Radebaugh ${ }^{\mathrm{g}}$, K. Arnold ${ }^{\mathrm{g}}$, J.W. Barnes ${ }^{\mathrm{h}}$, \\ K. Stephan ${ }^{i}$, R. Jaumann ${ }^{i}$, C. Sotin ${ }^{j}$, R.H. Brown ${ }^{k}$, R.D. Lorenz ${ }^{1}$, E.P. Turtle ${ }^{1}$
}

${ }^{a}$ Laboratoire Astrophysique, Instrumentation et Modélisation (AIM), CNRS-UMR 7158, Université Paris-Diderot, CEA-Saclay, 91191 Gif sur Yvette, France

b Laboratoire Atmosphères, Milieux, Observations Spatiales (LATMOS), UVSQ /CNRS/Paris VI, UMR 8190, 78280 Guyancourt, France

${ }^{\mathrm{c}}$ Planetary Science Institute, 1700 East Fort Lowell, Suite 106, Tucson, AZ 85719-2395, USA

d Laboratoire de Planétologie et Géodynamique (LPGNantes), CNRS-UMR 6112, Université de Nantes, 44322 Nantes, France

e Laboratoire Matière et Systèmes Complexes (MSC), CNRS-UMR 7057, Université Paris Diderot, 75205 Paris, France

${ }_{\mathrm{f}}^{\mathrm{f}}$ Institut de Physique du Globe de Paris (IPGP), Laboratoire de Dynamique des Fluides Géologiques, 75005 Paris, France

${ }^{\mathrm{g}}$ Department of Geological Sciences, Brigham Young University, Provo, UT 84602, USA

${ }^{\mathrm{h}}$ Department of Physics, University of Idaho, Moscow, ID 83844, USA

${ }^{\mathrm{i}}$ German Aerospace Centre (DLR), Institute of Planetary Research, 12489 Berlin, Germany

jJohns Hopkins University Applied Physics Laboratory, Laurel, MD 20723, USA

${ }^{\mathrm{k}}$ Department of Planetary Sciences, University of Arizona, Lunar and Planetary Laboratory, Tucson, AZ 85721-0092, USA

${ }^{1}$ Johns Hopkins University Applied Physics Laboratory, Laurel, MD, USA

\section{A R T I C L E I N F O}

\section{Article history:}

Available online 23 November 2013

\section{Keywords:}

Titan, surface

Radar observations

Infrared observations

Geological processes

\begin{abstract}
A B S T R A C T
Vast fields of linear dunes have been observed in the equatorial regions of Titan, Saturn's largest moon. As the Cassini mission, in orbit around Saturn since July 2004 and extended until May 2017, carries on, the high-resolution coverage of Titan's surface increases, revealing new dune fields and allowing refinements in the examination of their properties. In this paper, we present the joint analysis of Cassini's microwave and infrared global scale observations of Titan. Integrating within an up-to-date global map of Titan all the Cassini RADAR and VIMS (Visual and Infrared Mapping Spectrometer) images - the latter being empirically corrected for atmospheric scattering and surface photometry, from July 2004 through July 2013 and June 2010 respectively, we found very good qualitative and quantitative spatial matching between the geographic distribution of the dune fields and a specific infrared spectral unit (namely the "dark brown" unit). The high degree of spatial correlation between dunes and the "dark brown" unit has important implications for Titan's geology and climate. We found that RADAR-mapped dunes and the "dark brown" unit are similarly confined within the equatorial belt $\left( \pm 30^{\circ}\right.$ in latitudes) with an equivalent distribution with latitude, suggesting an increasing sediment availability and mobility at Titan's tropics relative to higher latitudes, compatible with the lower ground humidity predicted in equatorial regions by General Circulation Models. Furthermore, the strong correlation between RADAR-mapped dunes and the VIMS "dark brown" unit (72\%) allows us to better constrain the total surface area covered by dune material, previously estimated from the extrapolation of the RADAR observations alone. According to our calculations, dune material cover $17.5 \pm 1.5 \%$ of Titan's surface area, equivalent to a total surface area of $14.6 \pm 1.2$ million $\mathrm{km}^{2}(\sim 1.5$ times the surface area of Earth's Sahara desert). The VIMS "dark brown" coloration of the dune material is here confirmed at large spatial scale. If the sand particle composition is dominated by solid organics produced in and settling from the atmosphere, as supported by our spectral modeling and by previous spectral analysis, microwave radiometric data and atmospheric modeling, dune fields are one of the major surface hydrocarbon reservoirs on Titan. Assuming two possible scenarios for the sand distribution (either the sand is (1) entirely trapped in dune landforms, or (2) trapped in dunes at places where dune landforms are firmly observed and in sand sheets elsewhere), we estimate the volume of hydrocarbons trapped in the dune sediment to be comprised between 1.7 and
\end{abstract}

* Corresponding author. Address: Laboratoire AIM, Université Paris Diderot, Paris

7, CEA-Saclay, DSM/IRFU/SAp, Centre de l'Orme des Merisiers, bât. 709, 91191 Gif/

Yvette Cedex, France. Fax: +33 (0)1 69086577

E-mail address: sebastien.rodriguez@cea.fr (S. Rodriguez). 
$4.4 \times 10^{5} \mathrm{~km}^{3}$, corresponding to an average total mass of $230,000 \mathrm{GT}$, in comparison with $\sim 4000$ 30,000 GT of hydrocarbons in the polar lakes and seas. This indicates a maximum age for the dune sediments of $\sim 730$-Myr, consistent with estimations of the ages of the current Titan's atmospheric methane and surface.

(c) 2013 Elsevier Inc. All rights reserved.

\section{Introduction}

Saturn's largest moon Titan has a cold, hazy, dense nitrogenand hydrocarbon-rich atmosphere. This planet-sized icy moon has a complex climatic system (see Lebonnois et al., 2009 for a review), with hydrocarbon seasonal cycles including clouds (Rodriguez et al., 2009, 2011; Brown et al., 2010; Turtle et al., 2009, 2011a; Le Mouélic et al., 2011) and rainfall (Turtle et al., 2011b; Barnes et al., 2013), that globally tends to transport humidity from the equator to the poles (Rannou et al., 2006; Mitchell et al., 2006; Mitchell, 2008; Schneider et al., 2012). Since 2004, the Cassini orbiter has been continuously providing a wealth of images of the surface of Titan at different wavelengths and with unprecedented resolution (down to $\sim 200 \mathrm{~m}$ for the RADAR imager). Images from the ISS (Imaging Science Sub-system) cameras, the VIMS (Visual and Infrared Mapping Spectrometer) instrument and the RADAR experiment in SAR (Synthetic Aperture Radar) mode, all on board the Cassini spacecraft, have revealed the presence of landforms strongly linked to the climatic activity of the moon: hydrocarbon lakes and seas at high latitudes (e.g. Stofan et al., 2007), complex networks of fluvial channels at all latitudes (e.g. Elachi et al., 2006) and vast fields of dunes mostly around the Equator (e.g. Lorenz et al., 2006). The latitudinal distribution of these features is indicative of the different types of climates that Titan experiences or has experienced in the past. Dunes, in particular, provide a powerful tool to investigate the sedimentary and climatic history of the arid and/or semi-arid environments likely to prevail at Titan's tropics.

The thousands of dunes observed by Cassini on the surface of Titan, globally organized in vast dune fields, are mainly confined to the equatorial belt, within $\pm 30^{\circ}$ in latitude, and almost encircle the globe in longitude, except in the Xanadu region $\left(70^{\circ} \mathrm{W}-140^{\circ} \mathrm{W}\right.$, e.g. Radebaugh et al., 2011) where dunes are absent. The high resolution RADAR SAR images allowed estimation of their main morphological properties. Titan's dunes have a width of $\sim 1 \mathrm{~km}$, a spacing of $1-3 \mathrm{~km}$, lengths of many tens to a few hundreds of km (Lorenz et al., 2006; Radebaugh et al., 2008; Lorenz and Radebaugh, 2009), and their heights have been estimated by photo- and radar-clinometry to $\sim 100 \mathrm{~m}$ (Barnes et al., 2008; Neish et al., 2010). Nearly all of them are radar-dark, linear in form and similar in size and morphology to linear dunes typically found in large sand seas on Earth, e.g. in the Namib, Chinese or Saudi Arabian deserts (Lancaster, 1995). Cassini VIMS and RADAR observations at lower resolution have also shown that both the infrared behavior and the microwave emission from the dune fields are strongly suspected to be compatible with "sand" particles dominated by solid organics, spectrally similar to atmospheric aerosols (Soderblom et al., 2007; Barnes et al., 2008; Clark et al., 2010; Le Gall et al., 2011; Hirtzig et al., 2013). The mechanical properties of Titan's dunes and their formation mechanism have also been investigated. Titan's low gravity $\left(1.35 \mathrm{~m} / \mathrm{s}^{2}\right)$ and slightly denser atmosphere than Earth's $\left(1.47 \times 10^{5} \mathrm{~Pa}\right)$ increase the mobility of particles. The theoretical "fluid" threshold friction speed required to initiate the formation of dunes (through the saltation of particles) under Titan's condition has been calculated as $0.03-0.06 \mathrm{~m} / \mathrm{s}$ (which corresponds to "real" near-surface wind speeds of $0.8-1.5 \mathrm{~m} / \mathrm{s}$ ), with an optimum saltation diameter of $200-600 \mu \mathrm{m}$ depending on the bulk composition of particles
(Greeley and Iversen, 1985; Allison, 1992; Lorenz et al., 1995, 2006; Kok et al., 2012; with an extended review in Lorenz, 2014). Kok et al. (2012) also defined the "impact" threshold as the threshold friction speed needed to sustain saltation. They calculated the "impact" threshold for Titan and showed that the ratio of the "impact" to "fluid" threshold speeds is greater than unity (as for Venus, but contrary to Earth and Mars). Saltation on Titan therefore needs greater winds to be sustained than to be initiated, primarily due to the thicker atmosphere which efficiently dissipates the vertical motion of saltating particles (Kok et al., 2012). The presence of dunes at Titan's tropics thus indicates (1) the production of a sufficient supply of saltatable particles, probably originated as photochemical end-products settling directly from the atmosphere, (2) the generation of winds capable of moving sand-sized particles by saltation, and (3) conditions dry enough to allow sand transport near equatorial latitudes.

The complex interplay between the hydrocarbon cycle and surface processes leading to the formation and dynamics of Titan's dunes, however, is far from being fully understood. The precise composition and mechanical properties of the dune sediment, its origins, sources, geographic coverage and total volume are still open questions that require further investigation. The total volume of organic sediment trapped in the dunes has been roughly evaluated to be between $\sim 10^{4}$ and $10^{5} \mathrm{~km}^{3}$ by Lorenz et al. (2006), by extrapolation of the area that dunes cover in the two RADAR SAR swaths acquired in February and October 2005 and thanks to their apparent correlation with the large infrared-dark regions found by ISS in equatorial regions. Subsequent SAR observations indicated that dunes may cover as much as $20 \%$ of Titan's total surface area (up to $40 \%$ of equatorial areas) (Radebaugh et al., 2008), allowing a re-evaluation of the total volume of sand-sized sediment between 2 and $8 \times 10^{5} \mathrm{~km}^{3}$ (Lorenz et al., 2008), suggesting that the dune system represents a major surface geologic feature. These numbers were recently updated by Le Gall et al. (2011) compiling the 27 RADAR SAR images available at that time, resulting, in a new estimate of the total surface area covered by dunes $(\sim 11-12.5 \%)$ and sediment volume $\left(0.5-5 \times 10^{5} \mathrm{~km}^{3}\right)$ by extrapolating the partial RADAR coverage to the whole surface of Titan.

Combining data from RADAR and infrared experiments from the Cassini orbiter offers an extraordinary powerful and complementary tool to explore the surface of Titan. It allows to jointly benefit from the high resolution of the SAR images on one side (enough to resolve individual dunes) and the spectral and spatial coverage of the ISS and VIMS observations on the other side. The combined use of microwave and infrared observations of Titan therefore allows not only to better constrain and quantify the total dune coverage, but also to provide more quantitative clues to their composition. Soderblom et al. (2007) and Barnes et al. (2008) were the first to thoroughly investigate the degree of correlation between infrared spectral units identified with VIMS and RADAR images of Titan's dunes. At regional scale, they clearly demonstrated that SAR dunes strongly correlate with a specific spectral unit showing up mainly in the equatorial belt in VIMS mosaics (the "dark brown" unit, suspected to be water ice poor - Barnes et al., 2007, 2008; Soderblom et al., 2007; Le Mouélic et al., 2008). Extending the work of Soderblom et al. (2007) and Barnes et al. (2008) at Titan's globe scale, Le Corre et al. (2008) calculated the correlation between SAR dunes and the VIMS "dark brown" 
unit to be more than $80 \%$, inferring a total dune coverage of $\sim 18 \%$ and a total "sand" volume of $\sim 3 \times 10^{5} \mathrm{~km}^{3}$. Although in agreement with both previous and following calculations, estimates of Le Corre et al. (2008) were obtained from a very preliminary study with only a limited set of observations (up to 2007 for RADAR SAR - from TA to T25 - and 2008 for VIMS observations - from TA to T42). Recently, Arnold et al. (2013) explored in a single sand sea the possible correlation between dunes seen in RADAR images and albedo units at $0.938 \mu \mathrm{m}$ in ISS images, extending the previous work of Lorenz et al. (2006). They found good qualitative correlation between dunes and the darkest ISS areas within a test zone located in Fensal and Aztlan areas. Using the global RADAR/ISS image coverage and the total sand area from RADAR and ISS in Fensal and Aztlan areas $\left(2.3\right.$ million $\left.\mathrm{km}^{2}\right)$, they extrapolated the total sand coverage on Titan to $14 \%$, or 12 million $\mathrm{km}^{2}$, close to the calculation of Le Gall et al. (2011). Arnold et al. (2013) also gave a new estimate of $1.5-3 \times 10^{5} \mathrm{~km}^{3}$ for the global sand volume.

As illustrated by the fluctuations in all the sediment volume estimates, despite the extensive body of work in mapping Titan's dunes, calculating the areas of the sand seas is very challenging given the partial coverage of RADAR images and low resolution of ISS/VIMS observations. Besides, the accurate analysis of infrared observations of Titan's surface is made complex due to the strong atmospheric contributions (gaseous absorption and haze scattering), especially at short wavelengths (below $3 \mu \mathrm{m}$ ). Thus, as Cassini will continue to observe Titan up to May 2017, one must take advantage of any significant progress in the coverage and method of processing of SAR and infrared data. Following the pioneering work of Soderblom et al. (2007), Barnes et al. (2008) and Le Corre et al. (2008), we present here detailed mapping and characterization of Titan's dune fields at the global scale, using an importantly extended set of RADAR and VIMS images (Section 2). Doing so, we significantly update the geographic distribution and the estimate of the total coverage of the dunes, and refine the correlation of different types of data (RADAR/SAR and VIMS) and the inventory of solid organics on Titan (Section 3). On this purpose, we use here a full global mosaic of VIMS images of Titan's surface empirically corrected for atmospheric contributions. The correlation between the dunes imaged by the RADAR/SAR and some infrared spectral units appearing in VIMS observations also provides new constraints on the dune compositional properties (Section 3).

\section{Global mapping of the dunes}

\subsection{Dune global mapping with the RADAR SAR data}

The Cassini RADAR instrument is a microwave sensor operating at a frequency of $13.78 \mathrm{GHz}(\lambda=2.17 \mathrm{~cm}, \mathrm{Ku}$ band $)$ and having three active (altimeter, scatterometer and Synthetic Aperture Radar, or SAR) and one passive working modes (radiometer) (Elachi et al., 2004).

For our mapping purposes, we restricted this study to datasets acquired by the SAR imaging mode of the Cassini RADAR. Depending on the altitude of Cassini during acquisition, RADAR images provide the best spatial sampling of the Cassini remote sensing payload when observing Titan, ranging from 0.2 to $2 \mathrm{~km} /$ pixel for the "regular" SAR mode, when the spacecraft is at closest approach, i.e. between 1000 and $4000 \mathrm{~km}$ altitude. RADAR images can also be acquired for altitudes greater than $10,000 \mathrm{~km}$. The RADAR is thus operating in the "High-altitude" SAR mode (also called HiSAR) and the resulting spatial sampling is lower, typically $>1 \mathrm{~km} /$ pixel (possibly up to $\sim 20 \mathrm{~km} /$ pixel). The RADAR imaging mode results in the production of swaths $120-450 \mathrm{~km}$-wide, at Cassini altitude of $1000-4000 \mathrm{~km}$, and about $5000 \mathrm{~km}$-long following the track of the spacecraft (Elachi et al., 2004).
Fig. 1a presents the map of Titan's surface obtained by mosaicking all the SAR and HiSAR images recorded between Titan's first close flyby TA (October 26th 2004) and flyby T92 (July 10th 2013), putting together a total of 149 individual images (46 SAR and 103 HiSAR images). This corresponds to an addition of 19 individual SAR images (and of all the HiSAR images) as compared to the dataset used by Le Gall et al. (2011) to map Titan's dunes. All the RADAR swaths have been reprojected into the sinusoidal equal area coordinate system (guaranteeing a simple and rigorous area calculation) and simple cylindrical coordinate system (only for visualization purposes) using the ISIS software (Integrated Software for Imagers and Spectrometers, Anderson et al., 2004) and then incorporated in a Geographic Information System (GIS). Relative co-registration errors between swaths are small, never exceeding $\sim 0.1-0.2^{\circ}$ in latitude or longitude.

Thanks to their integration into the GIS, the surface area of each individual swath has been automatically calculated (see 3rd column of Table 1), updating and extending the previous evaluations of Le Gall et al. (2011) and allowing the precise determination of the total surface area observed by the RADAR. At the end of July $2013,43.1 \%\left(\sim 35,900,000 \mathrm{~km}^{2}\right)$ of Titan's surface was thus covered by the highest spatial resolution SAR images. This increases by $\sim 10 \%$ the total surface coverage of SAR observations estimated from the map drawn by Le Gall et al., 2011. The RADAR coverage is further extended up to $58.4 \%\left(\sim 48,700,000 \mathrm{~km}^{2}\right)$ if all the SAR and HiSAR images are incorporated (Fig. 1a).

The spatial resolution of the SAR images allows individual dunes to be resolved, permitting the accurate identification and delineation of the dune regions, taking into account the exclusion of the radar-bright "inselbergs" or patches embedded within the dune fields (Fig. 1b and inset). It has been also possible to outline some more dunes within the lower-resolution HiSAR observations, but only for those down to $1.5-2 \mathrm{~km} /$ pixel of spatial sampling (which is the critical minimum limit of spatial sampling in order to resolve kilometer-sized features). As we manually outline dune fields, this results in small but unavoidable errors in the calculation of their total surface area. The visual uncertainty has been evaluated by drawing several times the geographic limits of dune fields over the same region. This leads to a conservative systematic uncertainty on the dune coverage and absolute surface area of $2 \%$.

In the 2004-2013 period, dunes appear in 27 SAR and 7 HiSAR images (Table 1), mainly at the tropics with no apparent longitudinal preference (except for the total absence of dunes in the Xanadu area). A few isolated dune-like features are detected at latitudes higher than $30^{\circ}$, in the southern $\left(\sim 40^{\circ} \mathrm{S}, \sim 35^{\circ} \mathrm{E}\right)$ and northern hemisphere $\left(\sim 50^{\circ} \mathrm{N}, \sim 45^{\circ} \mathrm{W}\right)$, the latter having been already reported by Radebaugh et al. (2012). We evaluate that dunes cover $13 \pm 2 \%$ of the $58.1 \%$ of Titan's surface covered by the SAR and HiSAR observations, considering only images having a sufficient spatial resolution to identify individual dunes by excluding HiSAR swaths with resolution coarser than $2 \mathrm{~km} /$ pixel (accounting for $0.3 \%$ of Titan's surface coverage), and taking into account the overlap between images and dunes observed on these images. $99.6 \%$ of the imaged dunes are found within the equatorial belt (within $\pm 30^{\circ}$ latitudes). The dune coverage as strictly observed by the RADAR thus represents a total surface area of $6,500,000 \pm 130,000 \mathrm{~km}^{2}$. This increases by almost a factor 2 the total area of dunes firmly observed at Titan's surface (compared to the previous estimate of Le Gall et al. (2011)), especially thanks to the addition of the T77 "equatorial" SAR swath which contains $72 \%$ of dunes (Table 1 ). A direct extrapolation from the RADAR fragmentary observations alone suggests that dunes may cover more than $\sim 23 \%$ of Titan's total surface area, equivalent to $\sim 19.2$ million $\mathrm{km}^{2}$ (more than 2 times greater than the Sahara desert surface area), or at least $\sim 22 \%$ ( $\sim 18.3$ million $\mathrm{km}^{2}$ ) if the dunes are confined within the 
(a)

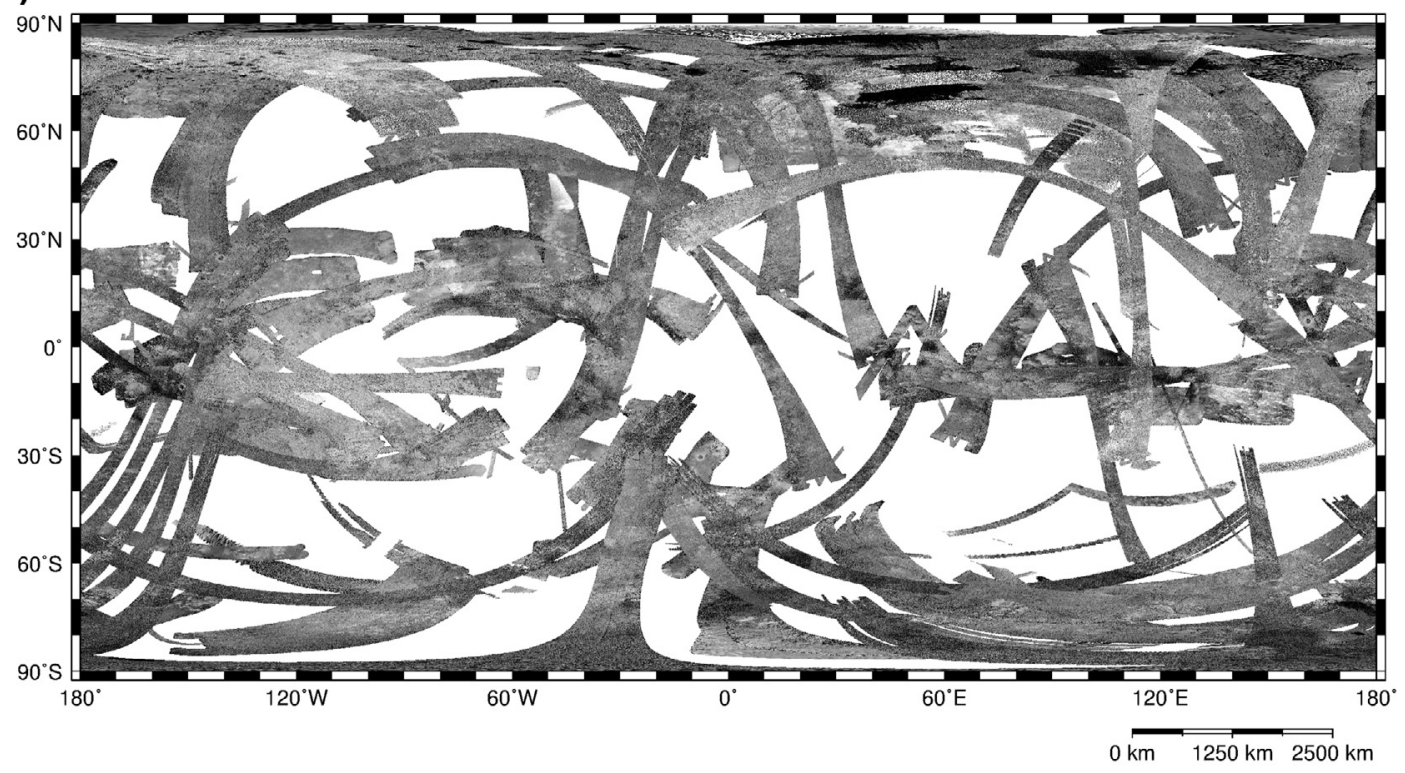

(b)

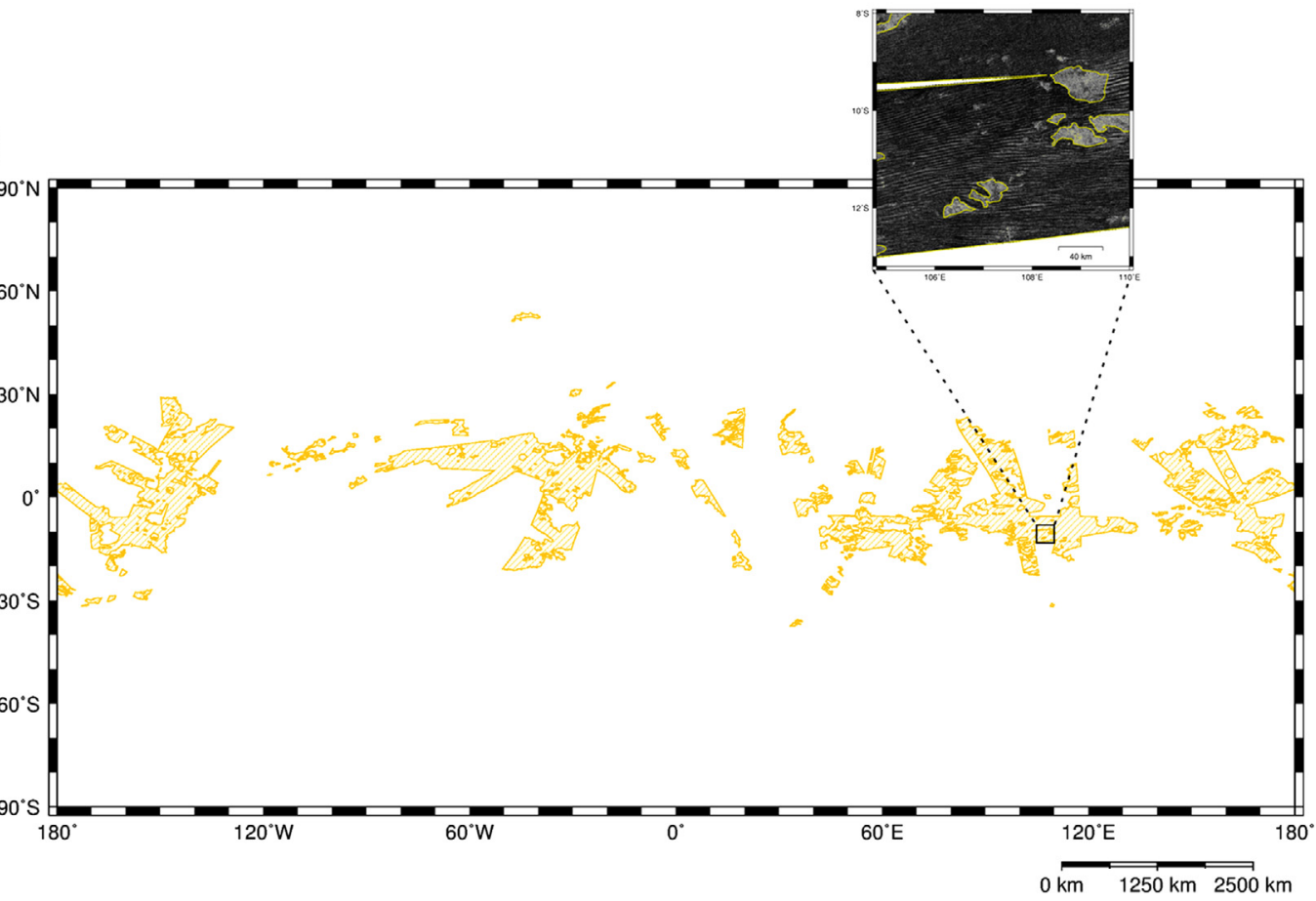

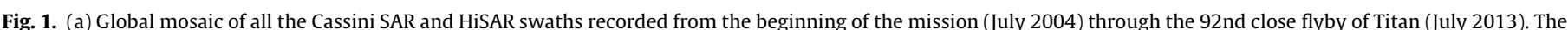

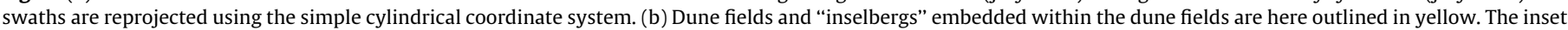
shows a zoomed view the RADAR map (a) with an example of how dune fields are delineated, excluding the "inselbergs" and embedded bright areas.

equatorial belt $\left( \pm 30^{\circ}\right.$ latitudes), $61.3 \%$ of which has been imaged after T92. Table 1 summarizes the information on the coverage, and the average latitude and longitude of all the dune fields that we have identified in the SAR and HiSAR swaths between TA (October 2004) and T92 flybys (July 2013).

\subsection{Infrared global mapping with the VIMS instrument and extraction of spectral units}

In order to complement the mapping of Titan's surface, we also built a global mosaic of surface observations recorded in the infrared by the VIMS instrument on board Cassini. The VIMS instrument is a camera that acquires images in 352 separate wavelengths and produces hyperspectral cubes (Brown et al., 2004). It is composed of two distinct detectors, VIMS-VIS in the visible (96 channels from 0.35 to $1.04 \mu \mathrm{m}$ ) with a spectral sampling of $7.3 \mathrm{~nm}$, and VIMS-IR in the near-infrared ( 256 channels from 0.88 to $5.11 \mu \mathrm{m}$ ) with a spectral sampling of $16.6 \mathrm{~nm}$. VIMS-IR is able to see Titan's surface in seven narrow atmospheric windows of weakest gaseous absorption (the "methane" windows) centered at 0.93, 1.08, 1.27, 1.59, 2.03, 2.7-2.8 and $5 \mu \mathrm{m}$ (Sotin et al., 2005). VIMS data that we use in this study are reduced to $I / F$ using the VIMS calibration pipeline, as described in Barnes et al. (2007).

All methane windows at wavelengths shorter than $5 \mu \mathrm{m}$ are strongly affected by atmospheric scattering due to the aerosols present in Titan's atmosphere - which blurs and masks the details 
Table 1

SAR and HiSAR observations of Titan's dune fields from TA through T92.

\begin{tabular}{|c|c|c|c|c|c|c|c|}
\hline Flyby & Date & $\begin{array}{l}\text { SAR swath } \\
\text { coverage }^{\mathrm{b}}(\%)\end{array}$ & $\begin{array}{l}\text { Dune coverage } \\
\text { within the } \\
\text { SAR swath }(\%)\end{array}$ & $\begin{array}{l}\text { Median of the swath } \\
\text { spatial sampling } \\
\text { [azimuth-range] } \\
\text { (km/pixel) }\end{array}$ & $\begin{array}{l}\text { Dune latitude } \\
\text { range }\end{array}$ & $\begin{array}{l}\text { Dune longitude } \\
\text { range }\end{array}$ & $\begin{array}{l}\text { Imaged dune } \\
\text { fields }{ }^{\mathrm{d}}\end{array}$ \\
\hline T3 & February 15, 2005 & 2.11 & 16.6 & $0.33-0.44$ & $1.5^{\circ} \mathrm{N}-22.5^{\circ} \mathrm{N}$ & $6.2^{\circ} \mathrm{W}-118.9^{\circ} \mathrm{W}$ & $\mathrm{F}$ \\
\hline T8 & October 28, 2005 & 2.08 & 51.2 & $0.3-0.42$ & $18.1^{\circ} \mathrm{S}-5.6^{\circ} \mathrm{S}$ & $41.8^{\circ} \mathrm{E}-176.6^{\circ} \mathrm{E}$ & $\mathrm{B}, \mathrm{SL}$ \\
\hline $\mathrm{T} 13$ & April 30, 2006 & 1.72 & 17.9 & $0.33-0.45$ & $16.7^{\circ} \mathrm{S}-4.2^{\circ} \mathrm{S}$ & $142.7^{\circ} \mathrm{W}-170.1^{\circ} \mathrm{W}$ & SL \\
\hline $\mathrm{T} 13(\mathrm{H})^{\mathrm{a}}$ & April 30, 2006 & 0.17 & 39.1 & $2.71-1.57$ & $10.5^{\circ} \mathrm{S}-2.5^{\circ} \mathrm{S}$ & $164.9^{\circ} \mathrm{W}-169.7^{\circ} \mathrm{W}$ & $\mathrm{SL}$ \\
\hline $\mathrm{T} 16$ & July 22, 2006 & 2.05 & 7.5 & $0.31-0.41$ & $14.4^{\circ} \mathrm{N}-25.9^{\circ} \mathrm{N}$ & $\begin{array}{l}140.9^{\circ} \mathrm{W}-149.6^{\circ} \mathrm{W} \\
11.1^{\circ} \mathrm{E}-19.9^{\circ} \mathrm{E}\end{array}$ & $\overline{\mathrm{A}}$ \\
\hline $\mathrm{T} 17$ & September 7, 2006 & 0.28 & 83.7 & $0.26-0.28$ & $2.5^{\circ} \mathrm{N}-14.9^{\circ} \mathrm{N}$ & $32.4^{\circ} \mathrm{W}-66.8^{\circ} \mathrm{W}$ & $\mathrm{F}$ \\
\hline T19 & October 6, 2006 & 2.22 & 7.5 & $0.3-0.41$ & $5.3^{\circ} \mathrm{S}-25.6^{\circ} \mathrm{N}$ & $30.2^{\circ} \mathrm{E}-45.3^{\circ} \mathrm{E}$ & $\mathrm{S}$ \\
\hline T19 (H) & October 6, 2006 & 0.33 & 6.5 & $0.61-1.19$ & $6.8^{\circ} \mathrm{N}-10.2^{\circ} \mathrm{N}$ & $49.5^{\circ} \mathrm{E}-54.8^{\circ} \mathrm{E}$ & S, B \\
\hline $\mathrm{T} 21$ & December 12, 2006 & 1.54 & 18.6 & $0.31-0.34$ & $19.5^{\circ} \mathrm{S}-13.8^{\circ} \mathrm{N}$ & $61.9^{\circ} \mathrm{E}-84.9^{\circ} \mathrm{E}$ & - \\
\hline $\mathrm{T} 23$ & January 13, 2007 & 2.05 & 7.9 & $0.3-0.42$ & $21.1^{\circ} \mathrm{S}-53.7^{\circ} \mathrm{N}$ & $\begin{array}{l}0-21.8^{\circ} \mathrm{E} \\
0-47.8^{\circ} \mathrm{W}\end{array}$ & $\begin{array}{l}\mathrm{S} \\
\mathrm{F}, \mathrm{A}\end{array}$ \\
\hline T25 & February 22, 2007 & 2.07 & 17.2 & $0.28-0.4$ & $20.8^{\circ} \mathrm{S}-31.2^{\circ} \mathrm{N}$ & $27.6^{\circ} \mathrm{W}-50.5^{\circ} \mathrm{W}$ & $\mathrm{F}, \mathrm{A}$ \\
\hline T28 & April 10, 2007 & 2.18 & 38.3 & $0.29-0.47$ & $18.9^{\circ} \mathrm{S}-33.4^{\circ} \mathrm{N}$ & $17.8^{\circ} \mathrm{W}-13.8^{\circ} \mathrm{W}$ & $\mathrm{F}, \mathrm{A}$ \\
\hline T29 & April 26, 2007 & 1.99 & 15.4 & $0.29-0.42$ & $3.6^{\circ} \mathrm{S}-24.8^{\circ} \mathrm{N}$ & $24.4^{\circ} \mathrm{W}-39.4^{\circ} \mathrm{W}$ & $\mathrm{F}, \mathrm{A}$ \\
\hline T36 (H) & October 2, 2007 & 0.47 & 47.6 & $0.76-1.04$ & $11.4^{\circ} \mathrm{S}-16.6^{\circ} \mathrm{N}$ & $153.1^{\circ} \mathrm{E}-172^{\circ} \mathrm{E}$ & SL \\
\hline T39 (H) & November 19, 2007 & 0.31 & 2.7 & $0.92-1$ & $1.8^{\circ} \mathrm{S}-1.3^{\circ} \mathrm{N}$ & $158.9^{\circ} \mathrm{E}-161.5^{\circ} \mathrm{E}$ & SL \\
\hline $\mathrm{T} 41$ & February 22, 2008 & 2.16 & 23.4 & $0.29-0.46$ & $28.6^{\circ} \mathrm{S}-12.7^{\circ} \mathrm{N}$ & $141.4^{\circ} \mathrm{E}-174.8^{\circ} \mathrm{W}$ & SL \\
\hline $\mathrm{T} 41(\mathrm{H})$ & February 22, 2008 & 0.39 & 40.3 & $0.61-1.28$ & $3^{\circ} \mathrm{S}-8.6^{\circ} \mathrm{N}$ & $45.7^{\circ} \mathrm{W}-65.8^{\circ} \mathrm{W}$ & A \\
\hline $\mathrm{T} 43$ & May 12, 2008 & 2.23 & 9.1 & $1.46-1.06$ & $0.9^{\circ} \mathrm{N}-26.2^{\circ} \mathrm{N}$ & $153.4^{\circ} \mathrm{E}-133.3^{\circ} \mathrm{W}$ & $\mathrm{SL}$ \\
\hline T44 & May 28, 2008 & 2.11 & 17.8 & $0.28-0.46$ & $4.9^{\circ} \mathrm{S}-21.1^{\circ} \mathrm{N}$ & $146.7^{\circ} \mathrm{E}-140.9^{\circ} \mathrm{W}$ & SL \\
\hline $\mathrm{T} 48$ & December 5, 2008 & 1.51 & 22.1 & $0.33-0.28$ & $15.8^{\circ} \mathrm{S}-27.4^{\circ} \mathrm{N}$ & $154.2^{\circ} \mathrm{E}-148.3^{\circ} \mathrm{W}$ & $\mathrm{SL}$ \\
\hline T49 & December 21, 2008 & 1.24 & 45.7 & $0.3-0.44$ & $22.6^{\circ} \mathrm{S}-23.3^{\circ} \mathrm{N}$ & $81.5^{\circ} \mathrm{E}-105.5^{\circ} \mathrm{E}$ & B \\
\hline T49 (H) & December 21, 2008 & 0.25 & 49.1 & $1.88-0.86$ & $7.5^{\circ} \mathrm{S}-10.7^{\circ} \mathrm{N}$ & $75.7^{\circ} \mathrm{E}-87.7^{\circ} \mathrm{E}$ & S, B \\
\hline T50 & February 7, 2009 & 0.81 & 18.1 & $0.28-0.27$ & $37.2^{\circ} \mathrm{S}-14.5^{\circ} \mathrm{N}$ & $33.3^{\circ} \mathrm{E}-59.2^{\circ} \mathrm{E}$ & $\mathrm{S}$ \\
\hline T50 (G) & February 7, 2009 & 0.61 & 46.7 & $2-2.42$ & $8.9^{\circ} \mathrm{S}-0.2^{\circ} \mathrm{S}$ & $81.8^{\circ} \mathrm{E}-109.1^{\circ} \mathrm{E}$ & $\mathrm{B}$ \\
\hline T55 & May 15, 2009 & 2.08 & 18.5 & $0.3-0.39$ & $31.5^{\circ} \mathrm{S}-22.8^{\circ} \mathrm{N}$ & $133.8^{\circ} \mathrm{W}-172.7^{\circ} \mathrm{W}$ & SL \\
\hline T56 & June 6, 2009 & 2.05 & 24.4 & $0.3-0.39$ & $30.2^{\circ} \mathrm{S}-22.5^{\circ} \mathrm{N}$ & $128.8^{\circ} \mathrm{W}-165.3^{\circ} \mathrm{W}$ & SL \\
\hline T57 & June 22, 2009 & 0.83 & 8.2 & $0.3-0.27$ & $29.8^{\circ} \mathrm{S}-10.7^{\circ} \mathrm{N}$ & $132.4^{\circ} \mathrm{W}-157.8^{\circ} \mathrm{W}$ & SL \\
\hline T58 & July 8, 2009 & 1.96 & 12.4 & $0.29-0.38$ & $16.1^{\circ} \mathrm{S}-5.6^{\circ} \mathrm{N}$ & $136.8^{\circ} \mathrm{W}-151.2^{\circ} \mathrm{W}$ & $\mathrm{SL}$ \\
\hline T61 & August 25, 2009 & 2.02 & 40.3 & $0.29-0.39$ & $14.8^{\circ} \mathrm{S}-8.3^{\circ} \mathrm{N}$ & $50.5^{\circ} \mathrm{E}-177.1^{\circ} \mathrm{W}$ & S-B-SL \\
\hline T64 & December 28, 2009 & 1.08 & 5.9 & $0.31-0.35$ & $12.1^{\circ} \mathrm{N}-16.5^{\circ} \mathrm{N}$ & $146.6^{\circ} \mathrm{E}-149.7^{\circ} \mathrm{E}$ & - \\
\hline T77 & June 20, 2011 & 1.06 & 72.0 & $0.33-0.43$ & $2.4^{\circ} \mathrm{N}-18.7^{\circ} \mathrm{N}$ & $33.2^{\circ} \mathrm{W}-95.1^{\circ} \mathrm{W}$ & $\mathrm{F}$ \\
\hline T84 & January 2, 2013 & 0.71 & 15.5 & $0.3-0.39$ & $6.5^{\circ} \mathrm{N}-16.3^{\circ} \mathrm{N}$ & 132.7E-148.4E & B \\
\hline T91 & May 23, 2013 & 1.02 & 1.9 & $\mathrm{~N} / \mathrm{A}$ & $15.5^{\circ} \mathrm{N}-19.5^{\circ} \mathrm{N}$ & $108.4 \mathrm{E}-112.9 \mathrm{E}$ & B \\
\hline T92 & July 10, 2013 & 2.03 & 13.9 & $\mathrm{~N} / \mathrm{A}$ & $31.8^{\circ} \mathrm{S}-19.4^{\circ} \mathrm{N}$ & $112.1 \mathrm{E}-117.9 \mathrm{E}$ & B \\
\hline
\end{tabular}

a $(H)$ and $(G)$ indicate HiSAR swaths.

b In percentage of Titan's total surface area, not accounting for possible overlap between swaths.

c In percentage of swath's total surface area, not accounting for possible overlap between swaths.

d If available, the names of the dune field(s) imaged during each flyby are noted: $A=A z t l a n, B=B e l e t, F=F e n s a l, S=S e n k y o, S L=S h a n g r i-L a$.

of the surface - whereas the $5 \mu \mathrm{m}$ window can be considered at first order as free of any haze scattering (Rodriguez et al., 2006). Atmospheric contribution, along with surface photometric behavior, result in significant artifacts expressed as seams in raw global mosaics because they are both highly dependent on the variation of the viewing conditions (incidence, emission, and phase angles).

Fig. 2a shows a color composite global mosaic of Titan's surface incorporating all VIMS observations between TA (October 26th, 2004) and T70 (June 21st, 2010), adding observations acquired during 28 extra Titan's flybys since the study of Le Corre et al. (2008). This noticeably extends the coverage and improves the average resolution of the equatorial regions. Furthermore, unlike the VIMS global mosaic of Le Corre et al. (2008), the map used in this study has been produced by applying the heuristic correction for atmospheric scattering and surface photometry described in Le Mouélic et al. (2012) and Cornet et al. (2012). This method, which includes recent refinements of the surface photometric function from Cornet et al. (2013), is based on empirical corrections (applied at the center of each methane window) for (1) the atmospheric scattering effects present in the short-wavelength methane windows, and (2) the surface photometry. Those corrections allow to globally homogenize the infrared map by diminishing the occurrence of seams, and significantly enhance subtle spectral heterogeneities between surface terrains, which are otherwise damped by atmospheric scattering, by getting closer to the true surface albedo.
As shown in Fig. 2a, at the end of June 2010, VIMS observations entirely covered the equatorial belt of Titan, with an average spatial resolution of $\sim 15 \mathrm{~km}$ (see also Le Mouélic et al., 2012). Titan's polar coverage with VIMS is also complete at a low spatial resolution, but does not appear in Fig. 2a as observations with the most extreme illumination and/or observation geometries were automatically filtered out by the correction algorithm (Le Mouélic et al., 2012). The VIMS map shows that equatorial regions are mostly dominated by three main spectral units, whose contrast is particularly enhanced thanks to our empirical corrections. Using a specific color scheme with red as the $5-\mu \mathrm{m}$ corrected channel, green as the $2.01-\mu \mathrm{m}$ corrected channel and blue as the $1.27-\mu \mathrm{m}$ corrected channel, the three spectral units visually appear, respectively (1) "bright" (the Xanadu area being part of it), (2) "dark brown", and (3) "dark blue" (Fig. 2a), the last two having been long suspected to be strongly linked to equatorial dune fields (Soderblom et al., 2007; Barnes et al., 2008).

We searched for spectral criteria to automatically extract the infrared "dark brown" and "dark blue" units from the corrected VIMS global map. Obvious advantages of this method are to avoid visual biases and to guarantee the spectral and physical consistency of the extracted areas. As we focus on the equatorial belt, all the regions poleward of $\pm 40^{\circ}$ in latitudes have been excluded from the extraction process. Besides, the equatorial regions benefit from the most favorable illumination and observation geometries, 
(a)

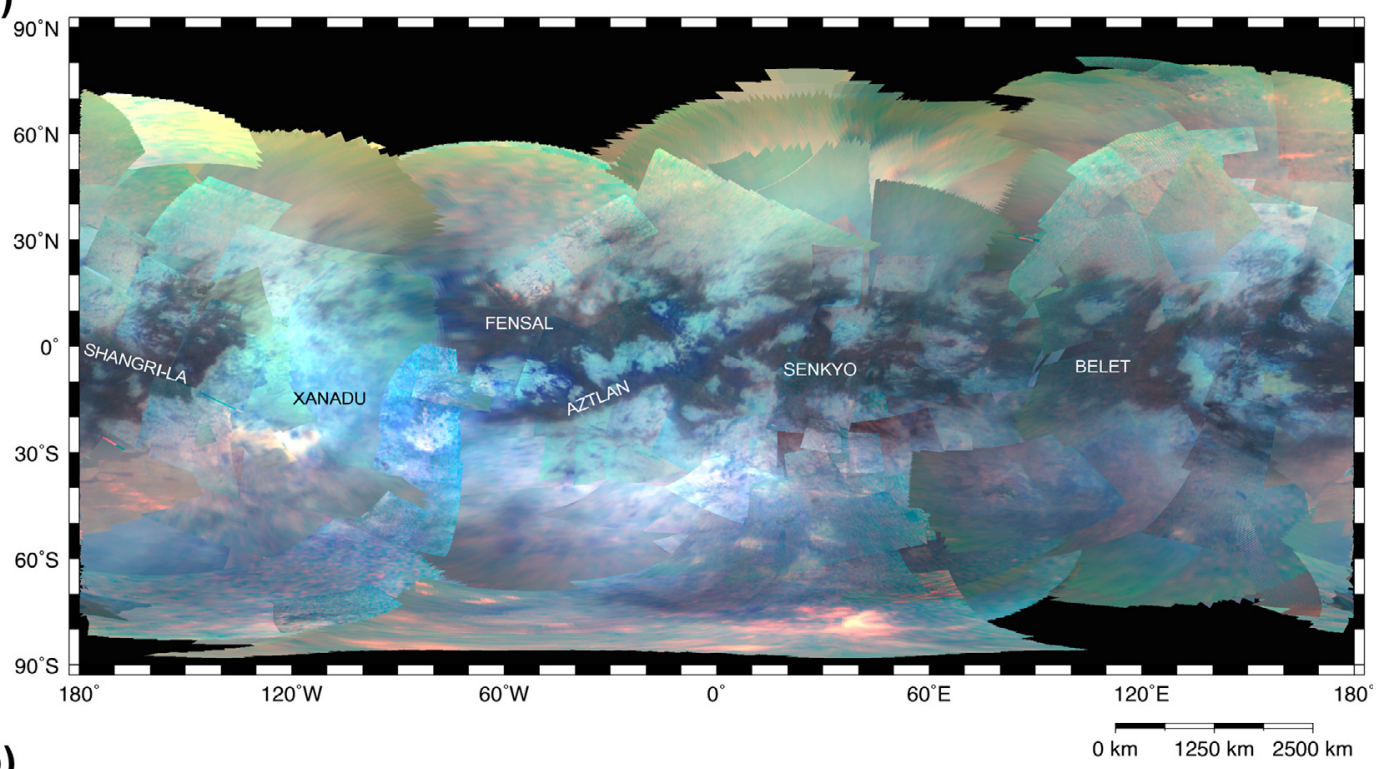

(b)

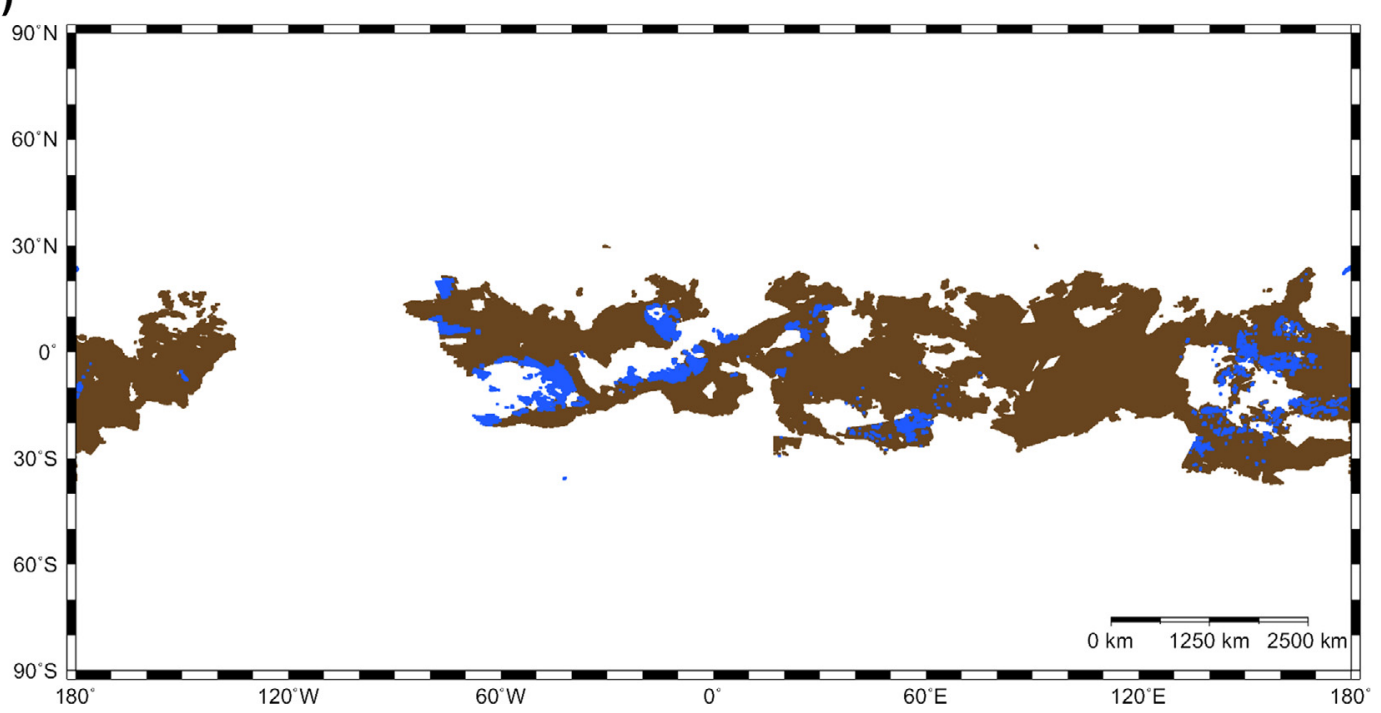

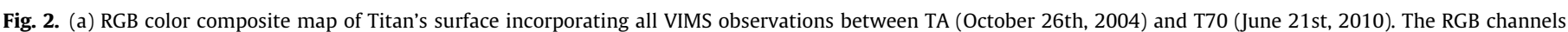

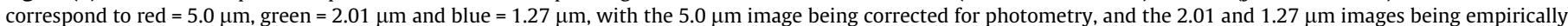

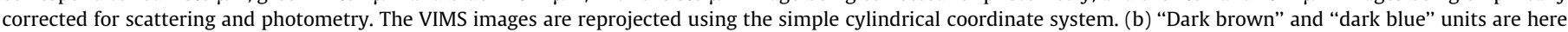
represented by the solid brown and blue areas (details on how those spectral units have been extracted from the VIMS global map are explicated in the text).

and therefore are where the atmospheric correction algorithm produces its best results. Looking at the spectra, "dark brown" and "dark blue" units are both characterized by very low $I / F$ in all the atmospheric windows compared to the equatorial "bright" unit and can be easily discriminated from the brightest terrains by simply applying $I / F$ thresholds. "Dark brown" and "dark blue" units are further separated owing to their subtle but discernible spectral differences, especially at the shortest wavelengths (below $3 \mu \mathrm{m}$ ). Indeed, "dark brown" spectra have a greater spectral slope between 1.59 and $2.78 \mu \mathrm{m}$ than between 1.27 and $2.01 \mu \mathrm{m}$, which is the exact opposite spectral behavior of the "dark blue" spectra. "Dark brown" spectra also systematically exhibit lower 1.27/ $1.59 \mu \mathrm{m}$ and $1.27 / 2.01 \mu \mathrm{m}$ ratios than the "dark blue's". Given all those criteria, we were able to automatically isolate the two dark "units" (Fig. 2b), which match extremely well the visual boundaries of the brownish and bluish areas of the VIMS mosaic (Fig. 2a), and calculate their respective surface areas. As the visual transition between spectral colors - whose sharpness is mainly limited by the average resolution of the global mosaic $(\approx 15 \mathrm{~km})$
- is slightly fuzzy, the localization of the spectral unit edges, and the subsequent calculation of their surface areas, suffer from uncertainties. This source of error has been evaluated by conservatively expanding and shrinking the borders of the spectral units by one 'unit' of average resolution ( $15 \mathrm{~km})$. We thus estimate that the "dark brown" and "dark blue" units cover $17.5 \pm 1.5 \%(14,600,000$ $\left.\pm 1,200,000 \mathrm{~km}^{2}\right)$ and $1 \pm 0.5 \%\left(840,000 \pm 410,000 \mathrm{~km}^{2}\right)$ of the total Titan's surface area respectively.

Fig. 3a shows the two infrared spectra extracted and averaged over the entire "dark brown" and "dark blue" units. These spectra are each built by combining the values of $I / F$ in the five atmospheric windows from 1.27 up to $5 \mu \mathrm{m}$, all corrected for atmospheric contribution. Even after the averaging over a very large number of spectra (more than 460,000 for the "dark brown" unit and more than 25,000 for the "dark blue" unit), the two resulting spectra still present substantial differences. The spectrum of the "dark blue" unit is significantly brighter at $1.27 \mu \mathrm{m}$, slightly brighter at $1.59 \mu \mathrm{m}$, and slightly darker at $2.01,2.75$ and $5 \mu \mathrm{m}$ than the spectrum of the "dark brown" unit. When we represent the 

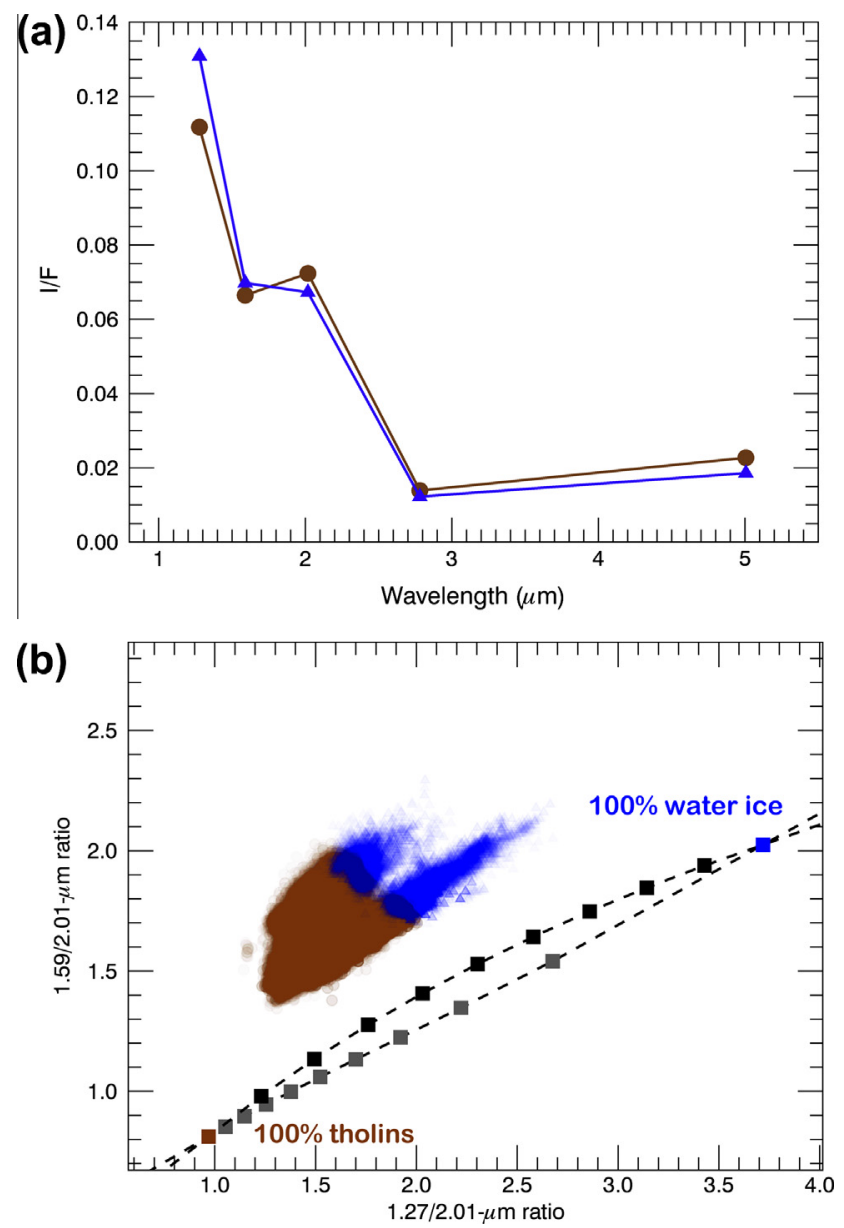

Fig. 3. (a) VIMS $I / F$ spectra averaged over the whole "dark blue" (blue triangles) and "dark brown" (brown circles) units displayed in Fig. 2b. The "dark blue" and "dark brown" spectra are averages of 25,129 and 466,819 spectra respectively. The $I / F$ values are taken at the center of 5 atmospheric windows (at 1.27, 1.59, 2.01, 2.75 and $5 \mu \mathrm{m}$ ), each corrected for atmospheric haze scattering and surface photometry. (b) Scatter plot of the $1.27 / 1.59$ vs $1.27 / 2.01 \mu \mathrm{m}$ spectral slopes for all the "dark brown" (brown circles) and "dark blue" (blue triangles) spectra, all being empirically corrected for atmospheric scattering and surface photometry. Squares denote the spectral slopes modeled for intimate (gray squares) or linear mixtures (black squares) of granular water ice and tholins by step of $10 \%$ of mixing, for grain sizes of $50 \mu \mathrm{m}$. The brown square is $100 \%$ of tholins and the blue square is $100 \%$ of water ice.

spectral slopes $1.27 / 1.59$ vs $1.27 / 2.01 \mu \mathrm{m}$ scatterplot for the two units (Fig. 3b), the spectral differences appear even clearer. In the scatterplot, the two units are both well confined in two small clusters with only few overlaps. This is indicative of two important properties for those spectral units: (1) the fact that the two units are confined in two distinct clusters in the scatterplot strongly suggests that they are representative of two different classes of surface composition, and (2) the fact that their spectra lie each in narrowed clusters shows that the two units have intrinsically a very high degree of spectral homogeneity, indicating that the two units are each covered by the same type of material.

As the spectra of the "dark brown" and "dark blue" units are all corrected for the atmospheric contribution (following the approach of Le Mouélic et al. (2012)), this allowed us to investigate further their most probable compositions. We calculated synthetic $I / F$ spectra of intimate and linear (or geographic) mixtures of granular surface composed of water ice and tholins (laboratory analogues to the atmospheric solid organics constituting Titan's settling haze). These synthetic spectra are computed for the average geometries of the "dark brown" and "dark blue" units, by using the formalism developed by Hapke (1993) and Lucey
(1998), including a Henyey-Greenstein phase function for the grains and multiple scattering between grains. The asymmetry factor for the grain phase function has been set to -0.4 (Buratti et al., 2006) and the average grain radius has been fixed at $50 \mu \mathrm{m}$. We used the refractive indexes measured by Warren (1984) for water ice and Khare et al. (1984) for tholins. Spectral slopes of the "dark brown" and "dark blue" units are thus compared with spectral slopes predicted from the granular surface modeling (Fig. 3b). The matching between observed and simulated slopes is sufficiently close to be informative. We are not able to discriminate between intimate or linear mixtures of water ice and tholins, though both or a combination of the two are still compatible with the observed spectral slopes. However, the general trend of the modeled spectral slopes leaves less ambiguity and advocates for a strong gradient in water ice/solid organics content between the two observed units. This unequivocally confirms the interpretation that "dark brown" terrains are largely dominated by solid organics similar to atmospheric aerosols. It also validates the enrichment in the fine-grained water ice content (or the pure water ice larger exposure) of the "dark blue" regions relative to the "dark brown" terrains (as suspected from the spectral slopes extracted from atmosphere-corrected Titan's spectra by Rodriguez et al., 2006; from uncorrected spectra by Soderblom et al., 2007; Barnes et al., 2008; Clark et al., 2010; in accordance with radiative transfer modeling of Hirtzig et al., 2013).

\section{Discussion}

Putting together the distribution of Titan's dunes inferred from the RADAR images and the mapping of the VIMS observations, it is possible to confirm and quantify, at the global scale, the correlation between the dune regions and the infrared "dark brown" unit. We discuss here the possible implications of such a correlation for the sand composition, the volume of the solid organic trapped in the dunes and the climatology.

\subsection{Latitudinal distribution of RADAR-mapped dunes and correlation with VIMS spectral units}

Fig. 4 shows the fractional surface area occupied by Titan's dunes observed by the RADAR as a function of latitude, updating and extending that of Le Gall et al. (2011). The dune surface area has been normalized by the total fractional area imaged by the RADAR (including SAR and HiSAR observations), in such a way that the calculation of fraction of dune coverage is not biased by the partial coverage of the RADAR observations. The latitudinal distribution of dunes is Gaussian-like to first order with a maximum fractional coverage of $\sim 60 \%$ at the equator, dropping down to no dunes for latitudes higher than $\pm 30^{\circ}$. The only exceptions are a few dunes found at $\sim 40^{\circ} \mathrm{S}$ and $\sim 50^{\circ} \mathrm{N}$ within isolated small areas morphologically (greater interdune areas) and spectrally (brighter at radar and infrared wavelengths) distinct from the majority of those observed around the equator (see Radebaugh et al., 2012).

This particular distribution of the dunes, generally associated with arid to semi-arid climates (e.g. Lancaster, 1995), strongly suggests that the efficiency of the sediment mobility monotonically decreases with latitude, possibly due to increasing ground humidity from the equator to the poles resulting in a declining availability in mobile sediment (Le Gall et al., 2012). Those observations are in general agreement with climate models that predict a global transport of humidity from the equator to the poles, inescapably drying the equatorial regions where arid conditions must prevail (Rannou et al., 2006; Mitchell et al., 2006; Mitchell, 2008; Schneider et al., 2012). The progressive poleward disappearance of dunes could also be partly attributed to a decrease in availability 


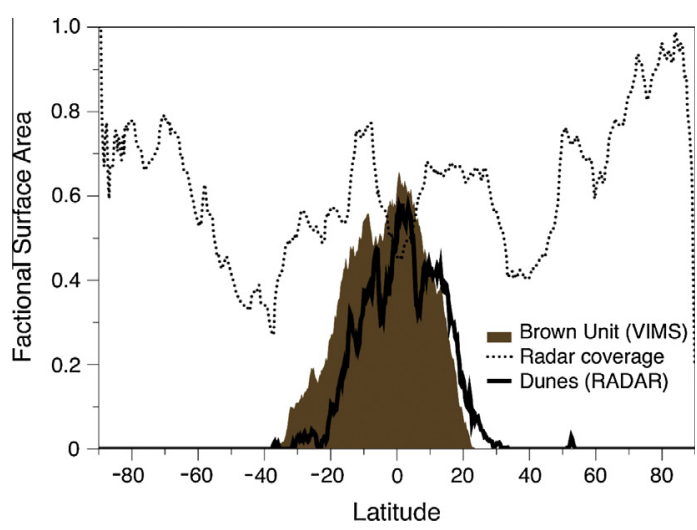

Fig. 4. Dune and "dark brown" unit latitudinal distributions. The surface area covered by dunes is normalized by the surface area sampled by Cassini SAR and HiSAR (down to the spatial sampling of $\sim 2 \mathrm{~km} /$ pixel) through T92, as a function of Titan's latitude (thick black curve). The latitude bin size is $1^{\circ}$. The dotted black line shows the fractional surface area of Titan covered by SAR + HiSAR swaths. It shows that all latitudes are significantly sampled by existing coverage.

of "dark brown" organic sediment (mid-latitudes being indeed dominated by bright infrared terrains, cf. Fig. 2a) and to less frequent storms able to produce sufficiently strong winds to mobilize the sediment (Schneider et al., 2012). Looking more carefully, the latitudinal distribution of dunes displays a slight hemispherical imbalance with fewer dunes in the southern hemisphere. If infrared bright equatorial terrains are more elevated than the equatorial "basins" where dunes seem to preferentially accumulate (Le Gall et al., 2012), this slight south/north asymmetry could be explained by the topography, because most of these highlands (equatorial bright terrains) are located in the southern hemisphere (Lorenz et al., 2013).

We also indicate in Fig. 4 the latitudinal fractional coverage of the VIMS "dark brown" unit inferred from the global VIMS spectral unit map (Fig. 2b). The latitudinal correspondence between the fractional coverage of the VIMS "dark brown" unit and the RADAR-mapped dunes is very good. The two distributions can be almost super-imposed, pointing toward a very high level of correlation between the dunes and the VIMS "dark brown" unit. The precise degree of spatial correlation is explored and quantified in the following section.

The latitudinal extent of the "dark brown" unit leads to an important conclusion. The infrared spectral signature of the bright mid-latitudes seems to indicate that sand has not settled in large exposed amounts at mid-latitudes in the present epoch. If the sand came from high latitudes, it must have been swept efficiently to the equatorial belt without leaving a lot en route in mid-latitudes. Another possibility is that the sand was never deposited away from the equator, which raises the questions of where it came from and how it formed.

3.2. Global geographic correlation between RADAR-mapped dunes and VIMS spectral units, dune global coverage and total sand volume: implication for Titan's global carbon cycle

We show in Fig. 5 (bottom) the spatial overlap between the dune fields extracted from the RADAR observations (see Fig. 1b) and the "dark brown" and "dark blue" units derived from the VIMS global map (see Fig. 2b). We observe a noticeably good correlation between the imaged dunes and the VIMS "dark brown" unit, extending at the global scale their very good latitudinal correlation

(a)

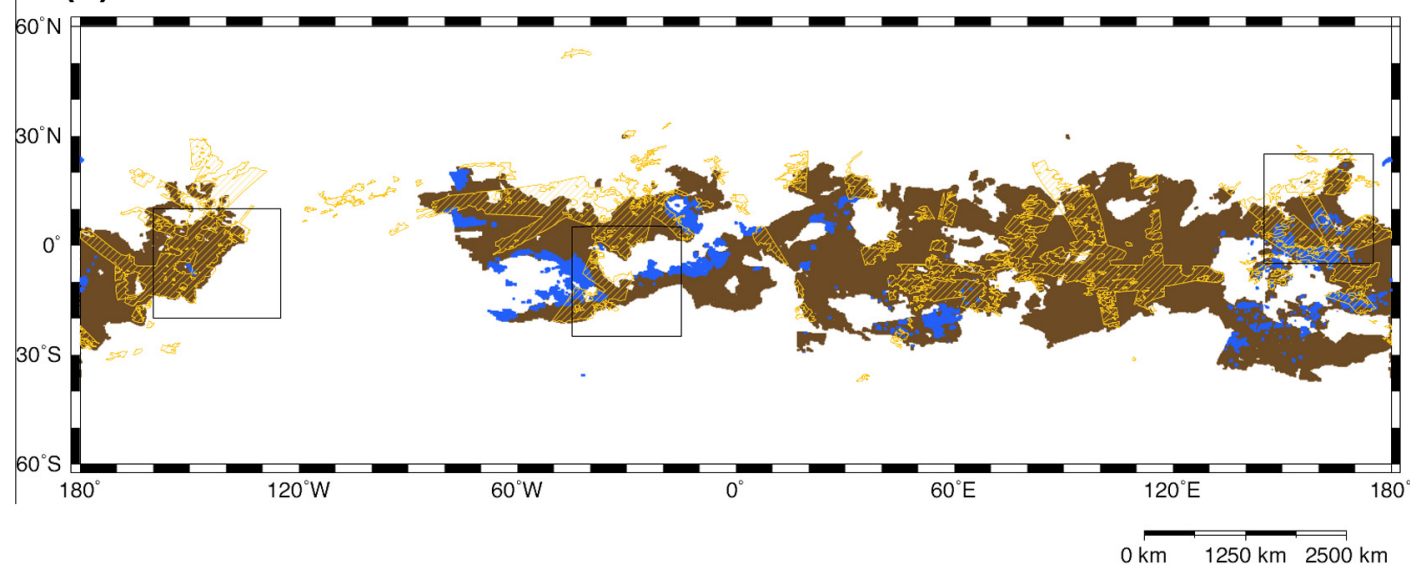

(b)

(c)

(d)
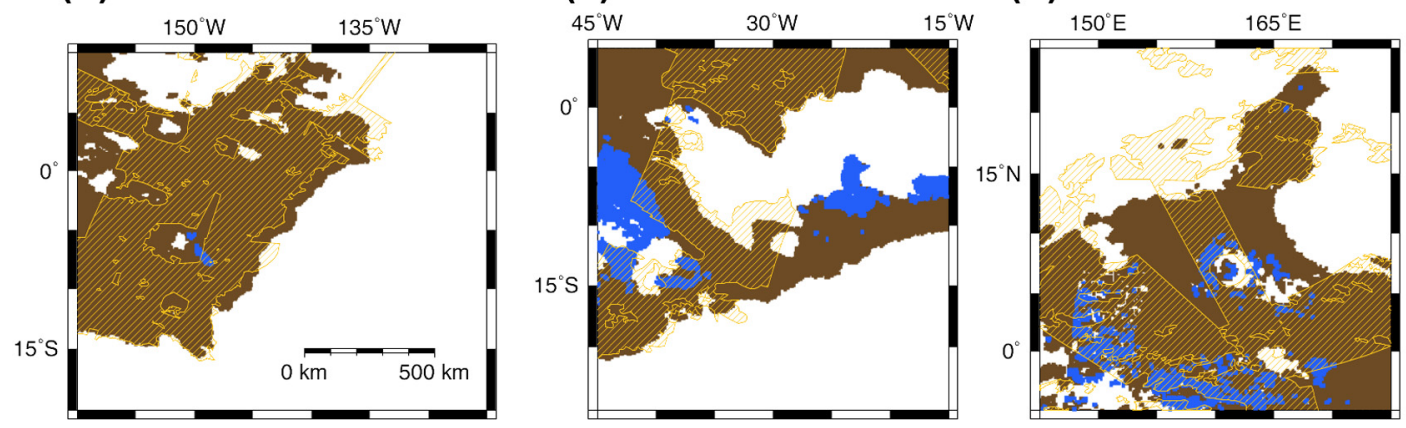

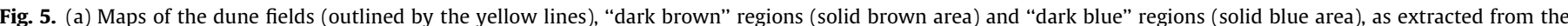

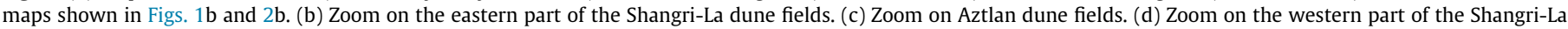
dune fields. The three insets illustrate the very good qualitative spatial correlation between the imaged dunes and the VIMS "dark brown" unit. 
(Section 3.1 and Fig. 4). Local visual examination (Fig. 5, insets for examples) shows that the edges of dune fields match most of the boundaries of the "dark brown" unit to within the resolution limit of the data.

Quantitative correlation calculations show that $72 \pm 3 \%$ of the imaged dunes (SAR and HiSAR with spatial sampling down to $\sim 2 \mathrm{~km} /$ pixel) lie in the "dark brown" unit. Conservative uncertainties have been computed taking into account (1) the visual $2 \%$ error in drawing the boundaries of the RADAR dune fields (see Section 2.1 ), (2) the $1.5 \%$ and $0.5 \%$ errors in estimating the areas covered by the "dark brown" and "dark blue" units respectively (caused by the low-resolution VIMS observations in some places and the resulting difficulty in visual identification of a sharp border for the more diffuse parts of the "dark brown" and "dark blue" units - see Section 2.2), and (3) co-registration errors due to remaining uncertainties on Titan's orbital parameters and Cassini pointing, leading to a global shift between RADAR and VIMS datasets which has been estimated to $0.5^{\circ}$ at maximum (mostly in longitude).

The geographic overlap between RADAR-mapped dunes and the VIMS "dark brown" unit is substantial and indicates that dune material composition is largely dominated by solid organics (see Section 2.2). Conversely, the correlation of dunes with the "dark blue" unit is much more fortuitous ( $2 \pm 1 \%$ of the observed dunes being infrared-"dark blue"). Only a few "dark blue" patches among the whole "dark blue" unit are found within the dune fields. But, even if incidental, the occurrence of such "dark blue" areas in dune regions may be very informative regarding the local heterogeneities in composition, morphological and/or textural properties of the dunes. We showed in Section 2.2 that the spectra modeling strongly favors local enrichment in water-ice of a solid organicwater ice granular mixture or a larger exposure percentage of pure water ice (i.e. a lack of sediments in the interdune areas) to explain the spectral behavior of the "dark blue" dunes, as it was previously anticipated (Barnes et al., 2008; Le Gall et al., 2011). This hypothesis is further supported by the fact that the "dark blue" unit occurs quasi-systematically as diffuse patches at borders delimiting dark and bright terrains, and may represents areas of intermediate organic sediment availability. Finally, a few dune fields are also found outside of the "dark brown" and "dark blue" regions. Most of them are isolated patches (also known as "cat scratches") surrounded by local reliefs where dunes are shorter and present very bright interdune areas at the RADAR wavelength. Those dune fields have probably interdune areas totally devoid of sediment, which make them appearing also globally brighter in the infrared lower-resolution images rather than brown or blue. Fig. 6 summarizes the actual interpretations of the dune infrared colors in terms of dune field morphology and progressive decrease in sediment availability.

The high level of qualitative and quantitative spatial correlation between the dunes and the "dark brown" unit that we infer from our global RADAR and VIMS maps confirms the strong bilateral connection between these geomorphological and spectral units. We can thus extrapolate with reasonably good confidence the extent of the dune fields (or at least the dune material) to the total area of the VIMS "dark brown" spectral unit. Given the spectral homogeneity of the "dark brown" unit, this also tells us that the dune material must be homogeneous in composition and grain size (sand-sized solid organics) over the total extent of the dune regions, in good agreement with the global homogeneity of the RADAR reflectivity and emissivity of the dune fields (Janssen et al., 2011) and consistent with dune formation processes. Therefore the dune system on Titan can be extended up to $17.5 \%$ of Titan's surface area (see Section 2.2). This corresponds to an area of $\sim 14.6$ million $\mathrm{km}^{2}$, much less than the over-estimated $\sim 18-19$ million $\mathrm{km}^{2}$ computed from the

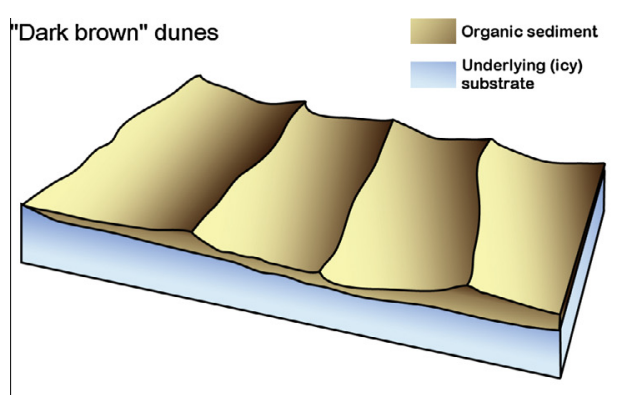

"Dark blue" dunes

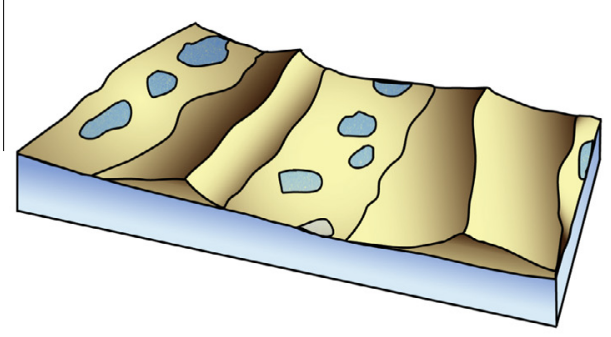

RADAR and VIMS brighter dunes

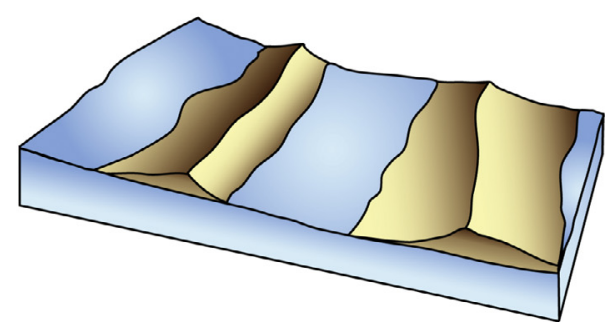

Fig. 6. Sketch of Titan's dune sediment coverage related to their infrared color. "Dark brown" dune systems (dunes and interdunes) are dominated by organic sediment. "Dark blue" and "bright" dunes are gradually depleted and devoid of sediment in the interdune areas.

arbitrary extrapolation using the RADAR observations alone (see Section 2.1).

We showed that the infrared "dark brown" unit is most likely dominated by solid organics, equivalent to the material composing the RADAR-mapped dunes. However, as infrared reflectivity of a surface is primarily sensitive to the composition and granularity of the first tens of microns of the material coating it, the "dark brown" spectral class, where no RADAR observations are available and where dunes cannot be resolved, may be caused by a thin coating independent of the underlying geologic feature, i.e. with or without dunes. We should therefore consider two possible alternative scenarios: either (1) the "dark brown" unit is entirely covered by dunes, or (2), more conservatively, only the "dark brown" areas overlapping RADAR-mapped dunes is covered by dunes, the rest of the "dark brown" unit being coated by the dune material but without dune landforms (i.e. sand sheets).

Considering an average dune height of $100 \mathrm{~m}$ (Barnes et al., 2008; Neish et al., 2010), a dune/interdune coverage fraction of 35-60\% (Savage et al., 2014), an average thickness of sediment covering the interdune (or covering the "dark brown" areas devoid of dunes) of $5 \mathrm{~m}$ (Lorenz et al., 2008), supposing a prismatic shape for the dunes, and taking into account the uncertainties on the surface areas of the RADAR-mapped dunes and "dark brown" unit, the total volume of organic sediments should be within the range $3-4.4 \times 10^{5} \mathrm{~km}^{3}$ for the scenario (1) and $1.7-2.5 \times 10^{5} \mathrm{~km}^{3}$ for the scenario (2).

Assuming a mass density of $800 \mathrm{~kg} \mathrm{~m}^{-3}$ for the organic sand particles, this corresponds to an equivalent of $136,000-$ 
$350,000 \mathrm{GT}$ (with an average value of $230,000 \mathrm{GT}$ ) of solid organic trapped in the dune sediments. These estimates make the equatorial sand one of the largest hydrocarbon reservoirs on Titan's surface and atmosphere, greater than the polar lakes and seas (ranging from 4000 to 30,000 GT, Lorenz et al., 2008; Sotin et al., 2012), the photochemical haze particles (0.14 GT, Sotin et al., 2012), and possibly the current atmospheric gases $(190,000 \mathrm{GT}$, Sotin et al., 2012). Considerable subsurface reservoirs of liquid or gaseous hydrocarbons may also exist on Titan (Hayes et al., 2008; Mousis and Schmitt, 2008; Cornet et al., 2012; Choukroun and Sotin, 2012), but their volumes are still impossible to evaluate.

Titan's atmospheric methane is irreversibly destroyed by solar photons and charged particles accelerated by Saturn's magnetosphere. A large fraction of the atmospheric methane destruction ends with the formation of complex organic aerosols that settle on the surface and form the primary source of organic sediments from which dune formation may be initiated. Taking our "average" value for the total mass of dune material and a formation rate for the atmospheric aerosols of $10-130 \mathrm{~kg} / \mathrm{s}$ (Rannou et al., 2003, 2004), the time required to form the total amount of dune material from the settling of photochemical aerosols ranges from 50- to 730-Myr, consistent with the age of the last global outgassing episode proposed by Tobie et al. (2006), Mandt et al. (2012) and Choukroun and Sotin (2012), and the estimate of the age of Titan's surface from crater counting (Wood et al., 2010; Neish and Lorenz, 2012).

\section{Conclusions}

This work has shown that a joint analysis of Cassini/RADAR and VIMS overlapping observations is an extremely powerful tool to explore the surface of Titan, providing additional constraints on the correlation between Titan's geomorphological and infrared spectral units. By significantly updating mosaics of RADAR and VIMS observations of Titan's surface, we were able to extract and delineate at the global scale both equatorial dunes from RADAR images and infrared spectral units from VIMS hyperspectral images. A new VIMS global mosaic corrected for the atmospheric contributions has been used in this study, improving and extending the work of Soderblom et al. (2007), Barnes et al. (2008) and Le Corre et al. (2008). RADAR-mapped dunes and the "dark brown" unit are similarly confined within the equatorial belt $\left( \pm 30^{\circ}\right.$ in latitudes) with an equivalent distribution with latitudes. This particular latitudinal distribution is indicative for the aridity of the climate prevailing at Titan's tropics, characterized by lower ground humidity and more frequent (but still episodic) energetic storms than at higher latitudes, increasing both sediment availability and mobility. At the global scale, we found an overall correlation of $72 \%$ between the imaged dunes and the equatorial infrared VIMS "dark brown" unit. The very high degree of global scale correlation conclusively proves the close link between both units, which was already proposed based on local studies (Soderblom et al., 2007; Barnes et al., 2008) and at the global scale from a limited set of observations (Le Corre et al., 2008). This correlation allowed us to extrapolate the extent of dune material to the whole surface area covered by the VIMS "dark brown" unit, that is to say $14.6 \pm 1.2$ million $\mathrm{km}^{2}$, updating and revising previous values evaluated using the partial coverage of RADAR images alone. Spectral modeling confirms that Titan's dune sediment (mostly "dark brown" in the infrared) is most plausibly largely dominated by solid organics similar to the photochemical atmospheric aerosols.

A refined estimate of the global dune material volume and distribution is essential to constrain Titan's total organic inventory and therefore to understand the carbon cycle on Titan. From our estimate of the total surface area covered by dune material and assuming two possible scenarios for the sand distribution (either the sand is (1) entirely trapped in dune landforms, or (2) trapped in dunes at places where dune landforms are firmly observed and in sand sheets elsewhere), we estimate the total volume of organic sand to be $1.7-4.4 \times 10^{5} \mathrm{~km}^{3}$. The average total amount of hydrocarbon trapped in Titan's sand is thus evaluated to $230,000 \mathrm{GT}$, confirming that dunes (and possibly sand sheets) are a major geological surface unit and the largest visible hydrocarbon reservoir on Titan. The volume and the spectroscopic properties of the sediment contained in Titan's dunes are consistent with organic products of atmospheric origin. Given the rate of atmospheric methane destruction into organic aerosols, we calculate a maximum age of $730 \mathrm{Myr}$ for the dune material, which agrees with the timeframe of the last episode of global methane outgassing (e.g. Tobie et al., 2006) and the young age of Titan's surface from crater counting (e.g. Wood et al., 2010).

All the results and refinements of our study, regarding the nature, origin and global distribution of Titan's dunes, not only can help the global circulation models to improve their prescriptions for tropical surface albedos and stratospheric haze production rates, but also bring strong constraints on the latitudinal distribution of ground humidity and strength of the near-surface winds. All the mapping shapefiles produced for this study (RADAR SAR and HiSAR coverages, RADAR-mapped dunes and VIMS spectral units) are shared with the community and accessible through the following website: http://www.exodunes.fr/WebGIS/TitanGIS.html.

The Cassini spacecraft continues to observe Titan up to the planned end of the Solstice mission in May 2017 and will record new RADAR and VIMS images. In particular, new RADAR and VIMS observations of the equatorial belt (up to the mid-latitudes) will complement the high-resolution and spectral coverage of this region. Yet, it is important to note that up to May 2017 the RADAR experiment will only acquire 8 new SAR swaths and most of them will pass above already observed equatorial regions, the major potential update above new equatorial (and "dark brown") regions being expected from the T113 pass in September 2015. The RADAR observations of Titan's dunes we compile in this paper are therefore almost complete for the Cassini's era.

Even so, more high-resolution VIMS observations at low- to mid-latitudes and better-quality corrections for atmospheric scattering and surface photometry are needed in order to sharpen the fuzziest edges of the "dark brown" unit and thus to improve their location. Future work will also consist in adding the ISS mosaics to the Titan's GIS. ISS provides images of Titan's surface at $0.93 \mu \mathrm{m}$ with an overall better spatial resolution than VIMS (except when VIMS is observing at the closest approach), providing additional constraints on the global correlation of dunes with infrared-dark regions. Because water ice is bright at $0.93 \mu \mathrm{m}$, ISS should be good at differentiating "dark brown" dunes from "dark blue" and "bright" deposits. All of this will better constrain both the nature and geographic distribution of Titan's sand and its total volume, which are crucial for a more complete understanding of Titan's climatology of and hydrocarbon cycle. Finally, the nature and origin of the singular infrared-"bluish" and "bright" areas within the dune fields will also deserve further investigations.

\section{Acknowledgments}

We sincerely thank the RADAR and VIMS Operations and Science Teams for their dedication in implementing and reducing the observations. We thank A.G. Hayes for very helpful discussions. We thank the two anonymous reviewers for useful and constructive comments. We also acknowledge support by the CNES (France), the Institut National des Sciences de l'Univers (INSU Programme National de Planétologie, France), the Agence Nationale de la Recherche (ANR Projects "EXODUNES" n¹2BS05001 
and "APOSTIC" ${ }^{\circ} 11$ BS56002, France), and the UnivEarthS Labex program at Sorbonne Paris Cité (ANR-10-LABX-0023 and ANR11-IDEX-0005-02). Part of this work has been performed at the Jet Propulsion Laboratory, California Institute of Technology under contract with NASA.

\section{References}

Allison, M., 1992. A preliminary assessment of the Titan planetary boundary layer In: Kaldeich, B. (Ed.), Proceedings of the Symposium on Titan, Toulouse, France, 9-12 September 1991, ESA SP-338, European Space Agency, Noordwijk, The Netherlands, 1992, pp. 113-118.

Anderson, J.A., Sides, S.C., Soltesz, D.L., Sucharski, T.L., Becker, K.J., 2004. Modernization of the integrated software for imagers and spectrometers. Lunar Planet. Sci. 35. Abstract \#2039.

Arnold, K., Radebaugh, J., Le Gall, A., Turtle, E.P., Lorenz, R.D., Garcia, A., 2013. Total sand volume estimates on Titan from Cassini SAR, HiSAR, and ISS. Lunar Planet. Sci. 44. LPI Contribution No. 1719, p. 2457.

Barnes, J.W., Brown, R.H., Soderblom, L., Buratti, B.J., Sotin, C., Rodriguez, S., Le Mouélic, S., Baines, K.H., Clark, R., Nicholson, P., 2007. Global-scale surface spectral variations on Titan seen from Cassini/VIMS. Icarus 186, 242-258.

Barnes, J.W., Brown, R.H., Soderblom, L., Sotin, C., Le Mouélic, S., Rodriguez, S., Jaumann, R., Beyer, R.A., Buratti, B.J., Pitman, K., Baines, K.H., Clark, R.N., Nicholson, P.D., 2008. Spectroscopy, morphometry, and photoclinometry of Titan's dunefields from Cassini/VIMS. Icarus 195 (1), 200-414. http://dx.doi.org/ 10.1016/j.icarus.2007.12.006.

Barnes, J.W. et al., 2013. Precipitation-induced surface brightenings seen on Titan by Cassini VIMS and ISS. Planet. Sci. 2, 1. http://dx.doi.org/10.1186/2191-2521-2-1.

Brown, R.H. et al., 2004. The Cassini Visual and Infrared Mapping Spectrometer (VIMS) investigation. Space Sci. Rev. 115, 111-168. http://dx.doi.org/10.1007/ s11214-004-1453-x.

Brown, M.E., Roberts, J.E., Schaller, E.L., 2010. Clouds on Titan during the Cassini prime mission: A complete analysis of the VIMS data. Icarus 205, 571-580.

Buratti, B.J. et al., 2006. Titan: Preliminary results on surface properties and photometry from VIMS observations of the early flybys. Planet. Space Sci. 54 (15), 1498-1509. http://dx.doi.org/10.1016/j.pss.2006.06.015.

Choukroun, M., Sotin, C., 2012. Is Titan's shape caused by its meteorology and carbon cycle? Geophys. Res. Lett. 39, L04201.

Clark, R.N. et al., 2010. Detection and mapping of hydrocarbon deposits on Titan. J. Geophys. Res. 115, E10005. http://dx.doi.org/10.1029/2009JE003369.

Cornet, T., Bourgeois, O., Le Mouélic, S., Rodriguez, S., Lopez Gonzalez, T., Sotin, C., Tobie, G., Fleurant, C., Barnes, J.W., Brown, R.H., Baines, K.H., Buratti, B.J., Clark, R.N., Nicholson, P.D., 2012. Geomorphological significance of Ontario Lacus on Titan: Integrated interpretation of Cassini VIMS, ISS and RADAR data and comparison with the Etosha Pan (Namibia). Icarus 218 (2), 788-806. http:// dx.doi.org/10.1016/j.icarus.2012.01.013.

Cornet, T. et al., 2013. Estimates of Titan's surface photometry in the $5 \mu \mathrm{m}$ atmospheric window using the Cassini Visual and Infrared Mapping Spectrometer (VIMS). Lunar Planet. Sci. 44. LPI Contribution No. 1719, p. 2048.

Elachi, C. et al., 2004. Radar: The Cassini Titan Radar Mapper. Sci. Rev. 115, 71-110. http://dx.doi.org/10.1007/s11214-004-1438-9.

Elachi, C. et al., 2006. Titan Radar Mapper observations from Cassini's T3 fly-by. Nature 441 (7094), 709-713. http://dx.doi.org/10.1038/nature04786.

Greeley, R., Iversen, J.D., 1985. Wind as a Geological Process on Earth, Mars, Venus and Titan. Cambridge Planetary Science Series No. 4. Cambridge University Press, Cambridge, London, New York, New Rochelle, Melbourne, Sydney.

Hapke, B., 1993. Theory of Reflectance and Emittance Spectroscopy, first ed. Cambridge University Press, Cambridge, UK.

Hayes, A.G. et al., 2008. Hydrocarbon lakes on Titan: Distribution and interaction with an isotropic porous regolith. Geophys. Res. Lett. 35 (L09), 204. http:// dx.doi.org/10.1029/2008GL033409.

Hirtzig, M., Bézard, B., Lellouch, E., Coustenis, A., de Bergh, C., Drossart, P., Campargue, A., Boudon, V., Tyuterev, V., Rannou, P., Cours, T., Kassi, S., Nikitin, A., Wang, L., Rodriguez, S., Le Mouélic, S., 2013. Titan's surface and atmosphere from Cassini/VIMS data with updated methane opacity. Icarus 226, 470-486. http://dx.doi.org/10.1016/j. icarus.2013.05.033.

Janssen, M.A., Le Gall, A., Wye, L.C., 2011. Anomalous radar backscatter from Titan's surface? Icarus 212 (1), 321-328. http://dx.doi.org/10.1016/j.icarus.2010. 11.026 .

Khare, B.N., Sagan, C., Arakawa, E.T., Suits, F., Callcott, T.A., Williams, M.W., 1984. Optical constants of organic tholins produced in a simulated titanian atmosphere: From soft X-ray to microwave frequencies. Icarus 60, 127-137.

Kok, J., Parteli, E.J.R., Michaels, T.I., Karam, D.B., 2012. The physics of wind-blown sand and dust. Rep. Prog. Phys. 75, 106901. http://dx.doi.org/10.1088/00344885/75/10/106901.

Lancaster, N., 1995. Geomorphology of Desert Dunes. Routledge, London.

Le Corre, L. et al., 2008. Global map of Titan's dune fields. In: European Planetary Science Congress, Proceedings of the Conference in Münster, Germany, p. 667.

Le Gall, A., Janssen, M.A., Wye, L.C., Hayes, A.G., Radebaugh, J., Savage, C., Zebker, H., Lorenz, R.D., Lunine, J.I., Kirk, R.L., Lopes, R.M.C., Wal, S., Callahan, P., Stofan, E.R., Farr, T.the Cassini Radar Team, 2011. Cassini SAR, radiometry, scatterometry and altimetry observations of Titan's dune fields. Icarus 213 (2), 608-624. http://dx.doi.org/10.1016/j.icarus.2011.03.026.
Le Gall, A., Hayes, A.G., Ewing, R., Janssen, M.A., Radebaugh, J., Savage, C., Encrenaz, P.the Cassini RADAR Team, 2012. Latitudinal and altitudinal controls of Titan's dune field morphometry. Icarus 217 (1), 231-242. http://dx.doi.org/10.1016/ j.icarus.2011.10.024.

Le Mouélic, S. et al., 2008. Mapping and interpretation of Sinlap crater on Titan using Cassini VIMS and RADAR data. J. Geophys. Res. 113, E04003. http:// dx.doi.org/10.1029/2007JE002965.

Le Mouélic, S. et al., 2011. Evolution the North Polar cloud on Titan monitored by The VIMS Imaging Spectrometer onboard Cassini. Planet. Space Sci. 60, 86-92. http://dx.doi.org/10.1016/j.pss.2011.04.006.

Le Mouélic, S. et al., 2012. Uniform global mapping of Titan's surface in several infrared atmospheric windows. Planet. Space Sci. 73 (1), 178-190. http:// dx.doi.org/10.1016/j.pss.2012.09.008.

Lebonnois, S., Rannou, P., Hourdin, F., 2009. The coupling of winds, aerosols and chemistry in Titan's atmosphere. Philos. Trans. R. Soc. A 367, 665-682. http:// dx.doi.org/10.1098/rsta.2008.0243.

Lorenz, R.D., 2014. Physics of saltation and sand transport on Titan: A brief review. Icarus 230, 162-167.

Lorenz, R.D., Radebaugh, J., 2009. Global pattern of Titan's dunes: Radar survey from the Cassini prime mission. Geophys. Res. Lett. 36 (3). http://dx.doi.org/10.1029/ 2008GL036850, CiteID L03202.

Lorenz, R.D., Lunine, J.I., Grier, J.A., Fisher, M.A., 1995. Prediction of aeolian features on planets: Application to Titan paleoclimatology. J. Geophys. Res. 88, $26377-$ 26386.

Lorenz, R.D. et al., 2006. The sand seas of Titan: Cassini RADAR observations of longitudinal dunes. Science 312, 724-727. http://dx.doi.org/10.1126/ science. 1123257.

Lorenz, R.D. et al., 2008. Titan's inventory of organic surface materials. Geophys Res. Lett. 35. http://dx.doi.org/10.1029/2007GL032118, CiteID L02206.

Lorenz, R.D., Stiles, B.W., Aharonson, O., Lucas, A., Hayes, A.G., Kirk, R.L., Zebker, H.A., Turtle, E.P., Neish, C.D., Stofan, E.R., Barnes, J.W.the Cassini RADAR Team, 2013. A global topographic map of Titan. Icarus 225, 367-377. http://dx.doi.org/ 10.1016/j.icarus.2013.04.002.

Lucey, P.G., 1998. Model near-infrared optical constants of olivine and pyroxene as a function of iron content. J. Geophys. Res. 103 (E1), 1703-1713.

Mandt, K.E. et al., 2012. The ${ }^{12} \mathrm{C} /{ }^{13} \mathrm{C}$ ratio on Titan from Cassini INMS measurements and implications for the evolution of methane. Astrophys. J. 749 (2), 14. http:// dx.doi.org/10.1088/0004-637X/749/2/160.

Mitchell, J.L., 2008. The drying of Titan's dunes: Titan's methane hydrology and its impact on atmospheric circulation. J. Geophys. Res. 113 (E8), CiteID E08015.

Mitchell, J.L., Pierrehumbert, R.T., Frierson, D.M.W., Caballero, R., 2006. The dynamics behind Titan's methane clouds. Proc. Natl. Acad. Sci. USA 103, 18421-18426.

Mousis, O., Schmitt, B., 2008. Sequestration of ethane in the cryovolcanic subsurface of Titan. Astrophys. J. 677, L67-L70.

Neish, C.D., Lorenz, R.D., 2012. Titan's global crater population: A new assessment Planet. Space Sci. 60, 26-33. http://dx.doi.org/10.1016/j.pss.2011.02.016.

Neish, C.D., Lorenz, R.D., Kirk, R.L., Wye, L.C., 2010. Radarclinometry of the sand seas of Africa's Namibia and Saturn's moon Titan. Icarus 208 (1), 385-394. http:// dx.doi.org/10.1016/j.icarus.2010.01.023.

Radebaugh, J., Lorenz, R.D., Lunine, J.I., Wall, S.D., Boubin, G., Reffet, E., Kirk, R.L., Lopes, R.M., Stofan, E.R., Soderblom, L., Allison, M., Janssen, M., Paillou, P. Callahan, P., Spencer, C.the Cassini RADAR Team, 2008. Dunes on Titan observed by Cassini RADAR. Icarus 194 (2), 690-703. http://dx.doi.org/10.1016/ j.icarus.2007.10.015.

Radebaugh, J., Lorenz, R.D., Wall, S.D., Kirk, R.L., Wood, C.A., Lunine, J.I., Stofan, E.R. Lopes, R.M.C., Valora, P., Farr, T.G., Hayes, A.G., Stiles, B., Mitri, G., Zebker, H., Janssen, M., Wye, L., Le Gall, A., Mitchell, K.L., Paganelli, F., West, R.D., Schaller E.L.the Cassini RADAR Team, 2011. Regional geomorphology and history of Titan's Xanadu province. Icarus 211 (1), 672-685. http://dx.doi.org/10.1016/ j.icarus.2010.07.022.

Radebaugh, J. et al., 2012. Stabilized dunes on Titan indicate changes in climate and surface processes. Lunar Planet. Sci. 43. LPI Contribution No. 1659, p. 2224.

Rannou, P., McKay, C.P., Cabane, R.D., 2003. A model of Titan's haze of fractal aerosols constrained by multiple observations. Planet. Space Sci. 51, 963-976.

Rannou, P., Hourdin, F., McKay, C.P., Luz, D., 2004. A couple dynamics-microphysics model of Titan's atmosphere. Icarus 170, 443-462.

Rannou, P., Montmessin, F., Hourdin, F., Lebonnois, S., 2006. The latitudinal distribution of clouds on Titan. Science 311, 201-205.

Rodriguez, S. et al., 2006. Cassini/VIMS observations of the Huygens landing site on Titan. Planet. Space Sci. 54, 1510-1523.

Rodriguez, S.Le. et al., 2009. Global circulation as the main source of cloud activity on Titan. Nature 459, 678-682. http://dx.doi.org/10.1038/nature08014.

Rodriguez, S., Le Mouélic, S., Rannou, P., Sotin, C., Brown, R.H., Barnes, J.W., Griffith C.A., Burgalat, J., Baines, K.H., Buratti, B.J., Clark, R.N., Nicholson, P.D., 2011 Titan's cloud seasonal activity from winter to spring with Cassini/VIMS. Icarus 216, 89-110. http://dx.doi.org/10.1016/j.icarus.2011.07.031.

Savage, C.J., Radebaugh, J., Christiansen, E.H., Lorenz, R.D., 2014. Implications of dune pattern analysis for Titan's surface history. Icarus 230, 180-190.

Schneider, T., Graves, S.D.B., Schaller, E.L., Brown, M.E., 2012. Polar methane accumulation and rainstorms on Titan from simulations of the methane cycle. Nature 481, 58-61. http://dx.doi.org/10.1038/nature10666.

Soderblom, L.A. et al., 2007. Correlations between Cassini VIMS spectra and RADAR SAR images: Implications for Titan's surface composition and the character of the Huygens probe landing site. Planet. Space Sci. 55 (13), 2025-2036. http:/ dx.doi.org/10.1016/j.pss.2007.04.014. 
Sotin, C. et al., 2005. Release of volatiles from a possible cryovolcano from nearinfrared imaging of Titan. Nature 438 (7043), 786-789. http://dx.doi.org/ 10.1038/nature03596.

Sotin, C., Lawrence, K.J., Reinhardt, B., Barnes, J.W., Brown, R.H., Hayes, A.G., Le Mouélic, S., Rodriguez, S., Soderblom, J.M., Soderblom, L.A., Baines, K.H. Buratti, B.J., Clark, R.N., Jaumann, R., Nicholson, P.D., Stephan, K., 2012. Observations of Titan's Northern lakes at $5 \mu \mathrm{m}$ : Implications for the organic cycle and geology. Icarus 221 (2), 768-786. http://dx.doi.org/10.1016 j.icarus.2012.08.017.

Stofan, E.R. et al., 2007. The lakes of Titan. Nature 445, 61-64. http://dx.doi.org 10.1016/S0019-1035(03)00125-8.

Tobie, G., Lunine, J., Sotin, C., 2006. Episodic outgassing as the source of atmospheric methane on Titan. Nature 440, 61-64. http://dx.doi.org/10.1038/nature04497.
Turtle, E.P. et al., 2009. Cassini imaging of Titan's high-latitude lakes, clouds, and south-polar surface changes. Geophys. Res. Lett. 36 (L2), 204. http://dx.doi.org/ 10.1029/2008GL036186.

Turtle, E.P. et al., 2011a. Seasonal changes in Titan's meteorology. Geophys. Res. Lett. 38, L03203. http://dx.doi.org/10.1029/2010GL046266.

Turtle, E.P. et al., 2011b. Rapid and extensive surface changes near Titan's equator: Evidence of April showers. Science 331, 1414-1417. http://dx.doi.org/10.1126/ science.1201063.

Warren, S.G., 1984. Optical constants of ice from the ultraviolet to the microwave. Appl. Opt. 23 (8), 1206-1225.

Wood, C.A., Lorenz, R.D., Kirk, R., Lopes, R.M.C., Mitchell, K.L., Stofan, E.R.the Cassini RADAR Team, 2010. Impact craters on Titan. Icarus 206, 334-344. http:/ dx.doi.org/10.1016/j.icarus.2009.08.021. 